\title{
Methoden altmesopotamischer Erziehung nach Quellen der altbabylonischen Zeit":
}

\author{
Von \\ KONRAD VOLK \\ Leipzig
}

Als Adam Falkenstein im Jahre 1953 im IV. Band dieser Zcitschrift seinen häufig zitierten Artikel "Die babylonische Schule" veröffentlichte, war dies der crste einer kleinen Anzahl von Abhandlungen über das babylonische Schulwesen, $\mathrm{dem}$ sich in den folgenden Jahren eine Reihe von Assyriologen, darunter J. J. A. van Dijk, ${ }^{1}$ C. J. Gadd, ${ }^{2}$ S. N. Kramer, ${ }^{3}$ B. Landsberger, ${ }^{4}$ F. R. Kraus, ${ }^{5}$ in jüngerer Zeit auch A. Sjöberg, ${ }^{7}$ W. H. Ph. Römer, ${ }^{7}$ H. L. J. Vanstiphout, ${ }^{8}$ H. Waetzoldt," Th. J. H. Krispijn, ${ }^{10}$ M. Civil" und C. Wilcke ${ }^{12}$ gewidmet haben. $\AA$. Sjöberg und M. Civil ist auch die Edition von wichtigen Literaturwer-

* Diese Untersuchung wurde durch die finanzielle Unterstützung der Deutschen Forschungsgemeinschaft im Rahmen des Forschungsprojektes „Kindheit, Erzichung und Ausbildung in Babylonien und Assyrien" ermoglicht. Für zahlreiche Hinweise und dic Bcnutzung von Kollationsergebnissen danke ich C. Wilcke, Leipzig, horzlich.

' J. J. A. van Dijk, L'Edubba et son csprit. In: La sagesse suméro-accadicnne, (Leiden 1953), S. $21-$ 27.

${ }^{2}$ C. J. Gadd, Teachers and Students in the Oldest Schools (London 1956).

S. N. Kramer, Die sumerische Schulc. WZUH V (1956), S. 695-704.

4 B. Landsberger, Scribal Concepts of Educacion. In: C. H. Kraeling and R. M. Adams, eds., City Invincible, S. 94-102 (Chicago 1960).

s F. R. Kraus, Briefschreibübungen im aitbabylonischen Schulunterricht. JEOL 16 (1964), S. 16-39.

- A. W. Sjöberg, The Old Babylonian Eduba, in: FS Th. Jacobsen, (AS 20, 1975), S. 159-179.

7 W. H. Ph. Römer, Iets over school en schoolonderricht in het oude Mcsopotamiē (Assen 1977).

${ }^{8}$ H. L. J. Vanstiphouc, How did they learn Sumerian?, JCS 31 (1979), 118-126.

- H. Waetzoldt, Keilschrift und Schulen in Mesopotamien und Ebla, in: L. Kriss-Rettenbeck/ M. Liedtke (cd.), Erziehungs- und Unterrichtsmethoden im historischen Wandel. Schriftenreihe zum Bayrischen Schulmuseum Ichenhausen, Bd. 4 (Bad Heilbrunn 1986), S. 36-50; ders.: Die Entwicklung der Naturwissenschaften und des naturwissenschaftlichen Unterrichts in Mesopotamien, in: J. G. Prinz von Hohenzollern/M. Liedtke (ed), Naturwissenschaftlicher Unterricht und Wissenschaftskumulation. Schriftenreihe zum Bayrischen Schulmuseum Ichenhausen, Bd. 7 (Bad Heilbrunn 1988), S. 31-49; ders.: Der Schrciber als Lehrer in Mesopotamien, in: Johann Georg Prinz von Hohenzollern/M. Liedtke (ed.), Schrciber, Magister, Lehrer. Schriftcnreihe zum Bayrischen Schulmuscum Ichenhausen, Bd. 8 (Bad Hcilbrunn 1989), S. 33-50.

10 Th. J. H. Krispijn "Naar School in her oude Mesopotamiē ${ }^{*}$. Phoenix 38 (1992), S. 21-33.

1 M. Civil, „Educarion in Mesopotamia“, in: Anchor Bible Dictionary II (New York 1992), S. 301305.

"C. Wilcke, „Schule und Literatur"; "Neusumerische und altbabylonische Schulbildung und Literatur"; "Schule und Literatur" (mittclbabylonisch/-assyrische Zeit), in: Schrift und Schriftlichkeit - Writing and its use. Fin interdisziplinäres Handbuch internationaler Forschung, Bd. 1, hg. von O. Ludwig (Berlin New York 1994), S. 494 f sub 2.4; 5. 496 f. sub 4.4, S. 499 f. sub 6.3. 
ken, die sich mit dem Thema Schule auseinandersetzen, zu verdanken. ${ }^{13}$ Für Adam Falkenstein bot sich seinerzeit eine sehr schmale Materialbasis, so daß er spezifischen Fragestellungen wie etwa den Methoden der Erziehung nicht en détail nachgehen konnte. Curriculum und Pensum standen bei ihm wie auch bei den jüngeren Untersuchungen als Untersuchungsgegenstand meist im Vordergrund. 14

Der Themenbereich Erziehung und Ausbildung im Alten Mesopotamien ist bisher nicht Gegenstand einer umfassenden Untersuchung gewesen. Das Reallexikon der Assyriologie (Bd. 2, S. 472-473) bietet gerade einmal 2 1/2 Spalten Text zum Stichwort ,Erziehung" unter ausschließlicher Berücksichtigung der Quellen des 1. Jahrtausends. So schreibt denn auch W. von Soden in seiner bekannten, im Jahre 1985 erschienen Einfübrung in die Altorientalistik: „Über die Grundsätze bei der Kindererziehung ist sehr wenig bekannt, da einige Hinweise auf die Erziehung der Prinzen und die Schulung von Schreibern nicht als für alle typisch gelten können". ${ }^{15}$ Eine ähnliche Sicht der Dinge vertrat jüngst auch $\mathrm{H}$. Waetzoldt. ${ }^{16}$

Ein Blick auf den Forschungsstand der Nachbardisziplinen wic jener der Ägypologie und derjenigen der Gräzistik verdeutlicht den völlig anderen wissenschaftsgeschichtlichen Standort der Assyriologie. Seit beinahe 40 Jahren gilt beispielsweise Hellmut Brunners Altägyptische Erziebung als Standardwerk der Ägyptologie. Zahlreiche Einzeluntersuchungen, ${ }^{17}$ aber auch umfangreiche Kompendien, wie Erika Feuchts Das Kind im Alten Ägypten ${ }^{18}$ wären zu nennen. Entsprechend weist das, Lexikon der Ägyptologie" nicht nur einen umfassenden Artikel zum Thema Erziehung auf, sondern differenziert, teilweise in der Folge Platonscher Überlegungen, soweit als möglich sorgfältig zwischen Ausbildung und Erziehung. ${ }^{19}$ Es erübrigt sich fast, auf eine ganze Reihe von Artikeln unter dem Oberbegriff Kind zu verweisen. Die noch unvergleichlich günstigere Ausgangsposicion der Gräzistik braucht an dieser Stelle wohl nicht hervorgehoben zu werden. So ist es kaum verwunderlich, daß in Standardwerken zur Geschich-

\footnotetext{
1s Vgl. unten Anm. 22 und 23.

${ }^{14}$ Dagegen hat sich J. J. A, van Dijk (s.o., Anm. 1) besonders mit dem intellektuellen Kontext des Edubba'a befasst.

is W. von Soden, Einführung in die Altorientalistik, S. 69.

16 "Für Mesopotamien fehlt eine zusammenfassende Untersuchung uber Schule und Erziehung, wie sie Hellmut Brunner bereits 1957 mit seinem Buch "Altagyptische Erziehung" vorgelegt hat. ${ }^{\alpha}$ Vl. H. Waetzoldt, Der Schreiber (wie Anm. 9), S. 33.

${ }^{17} \mathrm{Vgl}$. u.a. A. Théoridès, L'enfant dans les institutions pharaoniques. L'enfant dans les civilisations orientales - Het Kind in de oosterse Beschavingen (Leuven 1980), S. 89-102; ders. L'enfant dans le droit de l'Égypte ancienne. Receuil Jean Bodin 35 (1975), S. 81 ff,; E. Feucht, Geburt, Kindheit, Jugend und Ausbildung im Alten Ägypten. In: Zur Soxialgeschichte der Kindheit. Herausgegeben von J. Martin und A. Nitschke (Freiburg/München 1986).

"E. Feucht, Das Kind im Alten Ägypten. Die Stellung des Kindes in Familie und Gesellschaft nach altägyptischen Texten und Darstellungen (Frankfurt/New York 1995).

19 Vgl. hierzu die Diskussion bei H. Brunner (wie Anm. 16), S. 2.
} 
te der Erziehung wie etwa H.I. Marrous Histoire de l'éducation dans l'antiquite ${ }^{20}$ oder dem im Jahre 1986 erschienenen Band Zur Sozialgeschichte der Kindheit ${ }^{21}$ nur weniges oder im letzterem Falle sogar überhaupt nichts zur Erzichung in Mesopotamien zu finden ist.

Worin, so wird man zurechr fragen, ist nun dieses scheinbare Defizit der Assyriologie begründet? Es liegt, um es kurz zusammenzufassen, nicht daran, daß die Keilschrifüberlieferung kein Textmaterial zum Thema „Erziehung" zu bicten hätte. Ganz im Gegenteil. Die Informationsgrundlage ist durchaus gut, jedoch, und hier liegt dic wissenschaftsgeschichtliche Problemarik, extrem komplex, in den verschiedenen Perioden von dreitausend Jahren Keilschriftgeschichte ganz ungleich dokumenticrt und mit zahlreichen philologischen und edito-rischen Problemen behaftet. Gerade das sumerische Textmaterial der altbabylonischen Zcit, das neben anderem aufgrund seiner Dichte an Informationen zum Thema herangezogen werden muß, kann als Paradebeispiel für die etwas abstrakt geschilderte Problematik gelten: Obwohl weitgehend vollständig rekonstruierbar, liegt kaum eines der für dic gegebene Fragestellung relevanten literarischen Werke des Edubba'a, des, Tafelhauses', in hinreichender und somic zitierbarer Form ediert vor. Ließe sich für dic Schulsatire Der Vater und sein mißratener Sobn sowic die nachaltbabylonischen, sogenannten Examenstexte noch auf die Erst-Edirionen von Å. Sjöbcrg ${ }^{22}$ sowie die Teilbearbeitung der ,Edubba'a Regulations' von M. Civil ${ }^{23}$ verweisen, so bedarf die aus dem Jahre 1947 starnmende Bearbeitung von S. N. Kramers ,Schooldays' [hier: Der Sobn des Tafelhauses] auch aufgrund zahlreicher neuer und ergänzender Textzcugen einer Neuedition. ${ }^{24}$ Für die zentralen Werke der altbabylonischen Rangstreitliteratur (Streit zweier Schulabsolventen; Enkitalu und Enkibegal; Enkimansum und Girini'sas. ${ }^{25}$ Der Schreiber und sein Aufseber; Vorschriften des Edubba'a; Zwei Frauen $[A$ und $B]),{ }^{26}$ die bemerkenswerte Parallelen zu den lateinischen

20 Paris' 1955, 3. Aufl.

${ }^{21} \mathrm{Vgl}$. Anm. 17.

${ }^{22} \mathrm{Zu}$ Der Vater und sein mißratener Sobn vgl. A. Sjüberg, JCS 25 (1973), S. 109 ff.; eine Übcrsctzung bieter W. H. Ph. Römer, TUAT III/1, 5. 77-91; Examenstext A, vgl. A. Sjöbcrg, ZA 64 (1975), S. $137 \mathrm{ff}$.; Examenstext D, s. Å. Sjöberg, JCS 24 (1972), S. $126 \mathrm{ff}$; beide Examenstextc sind ers: nachaltbabylonisch ülserliefert.

23 Zu dem nachfolgend Edubba'a Regulations genannten Werk vgl. M. Civil, FS Birot, S. $67 \mathrm{ff}$.

${ }^{24}$ Für diese Schulsarire hat nur W. H. Ph. Römer (TUAT III/1, S. 68-77) eine neuere Übersetzung vargelegt.

is Zu ciner Übcrsetzung von Teilen dieses Streitgespräches vgl. W. H. Ph. Römer, TUAT III/1, S. 91-98.

26 Vollständige Textrekonstruktionen der hier genannten Streitgespräche gehon auf eigene Umschrifcen veröffentlichter Texte, sowie insbesondere auf die durch eine schr große Anzahl unpublizierter Texte komplettierten Files von M. Civil zurück, die dieser mir in überaus dankenswerter Weisc zur Einsiche überlassen hat. Ebenso zu Dank verpflichtet bin ich A. Cavigneaux, der mir sein unveröffentlichres MS von Zwer Fraken (A) zur Verfügung gestellt hat. 
Schülergesprächen der Humanisten aufweisen, liegen zwar eine Vielzahl von Texten und Fragmenten, aber keinerlei Editionen var. Diese befinden sich im Stadium der Vorbereitung durch M. Civil, Chicago, der auch in den demnächst erscheinenden Festschriften für W. G. Lambert und R. Borger ${ }^{27}$ weiteres, bisher unbekanntes Material zum altbabylonischen Schulunterricht veröffentlichen wird, das für die nachfolgenden Untersuchungen bereits herangezogen werden konnte.

Neben diese ungünstigen organisatorischen Voraussetzungen treten zahlreiche philologische, dic dem Versuch einer umfassenden und raschen Quellenanalyse entgegenstehen. Um kurz zu verdeutlichen, was damit gemeint ist, soll an einem Beispicl aufgezeigt werden, mit welchen Schwierigkeiten die philologische Analyse, die ja als Voraussetzung für jede weitergehende Interpretation zu gelten hat, bisweilen verbunden ist. Das für den thematischen Zusammenhang wichtige Sprichwort 23 der ,Proverb Collection 2' (SP 223$)^{2 \mathrm{r}}$ ist, ebenso wie manch anderes Sprichwort, in mehreren, hier zwei Versionen überliefert:

A) úku-re dumu-na tibir diš-àm šu nu-um-ši-in-du ${ }_{11}-r_{x}{ }^{\prime}$ gi $i_{16}$-sa da-ré-éš mu-un-[x]-níak-[àm]

B) úku-rc dumu-ni tibir diš-àm [šu mu-un-ši-in- du $\left.{ }_{11}\right]^{2} /$ gi $i_{16}$-sa da-ré-éš nu-mu-[ni-in-akàm].

Es fällt sofort auf, daß dic jeweils abschließende Verbalform in Version A) positiv formuliert, in Version B) jedoch ncgiert ist. Für die jeweils erste Verbalform ist in der Art eines Chiasmus eine jeweils entgegengesetzte Verbalpräfigierung wahrscheinlich, wenngleich nicht beweisbar. Unter der Voraussetzung, daß beide Versionen beabsichitigt und nicht in irgendeiner Form fehlerhaft und somit zufällig überliefert sind, sind sie nur dann inhaltlich analog verständlich, wenn man sie einmal als Satzaussage auffasst: A) „Ein Armer schlug sein Kind niemals mit der Faust. Als einen ,Schatz" behandelte er es", andererseits B) als Frage interpreticrt: „Schlug ein Armer sein Kind jemals mit der Faust? Behandelte er es nicht als Schatz?" Da formale Kriterien, etwa Interrogativpronomen, zur Bestimmung der Frage, inwieweit hier Fragesätze vorliegen könnten, fehlen, wäre es theoretisch auch denkbar, daß sogar die erstgenannte Version A) als Frage, B) als Satzaussage z.u verstehen ist. Damit wäre aber der Sinn der oben gegebenen Überserzung genau ins Gegenteil verkehrt: „Schlug ein Armer sein Kind niemals mit der Faust? Behandelte er es wic cin Schatz?"

Dieses Beispiel ist durchaus kein Einzelfall. Gerade in den Dialogen der Kontrahenten in der Rangstreitliteratur stellt sich, mit allen sich ergebenden Konsequenzen, oft die Frage, ob cin Aussage- oder Fragesatz vorlicgt. Daneben erschwert auch dic stcllenweise ironisch-satirische Überzeichnung der Verhält-

$\mathfrak{v}$ Tikip santakki mala bašınu ... Eine Festschrift für Rykle Burger zu seinem 65. Grcburtstage am 24. Mai 1994. Herausgegeben von Stefan M. Maul, Groningen 199.

28 Zur Textüberlieferung dieses Sprichwortes vgl. $\Lambda \mathrm{nm}$. 114. 
nisse und manche Übertreibung in den Aussagen der Kontrahenten den Blick auf die Wirklichkeit. Glücklicherweise haben wir es abcr nicht nur mit Problemfällen zu tun. Manches ist, zumindest an der Oberfläche, leichter verständlich, und insbesondere dic altbabylonisch-akkadischen Bricfe, besonders diejenigen aus Mari, bieten ein schönes und gut crfasstes Quellenmaterial für unsere Fragestellung, soweit es dic Erziehung bürgerlicher wic auch privilegierter Schichten anbetrifft.

Unter den gegebenen Voraussetzungen sind aus dem Themenbereich der Erziehung, der, soweit immer möglich, von demjenigen der Ausbildung unterschicden werden sollte, am chesten die Methoden der Erzichung ${ }^{29}$ greifbar, anhand der Qucllen nachvollziehbar und im Vergleich zu den Ergebnissen der Nachbardisziplinen darstellbar, handelt es sich doch insbesondere bei den disziplinarischen Mittcln oftmals um konkretc Zusammenhänge, um die Schilderung von Actio und Reactio. Inwicweit diese Erziehungsmethoden in einer babylonischen Paideia verankert sind, muß zukünftigen (in Vorbereitung befindlichen) Untersuchungen überlassen bleiben.

Der Terminus Erziehung ist vorläufig nur in einem sehr allgemeinen Sinnc zu verwenden, da eine für das Altc Mesopotamien individuclle Bcgriffsabgrenzung erst dann möglich sein wird, wenn alle zur Frage stehenden Quellen abschlicBend analysiert sind. Weitcrhin gilt es zu berücksichtigen, daß bisherige Darstellungen und Definitionen vor- antiker' Erziehung überproportional von den Aussagen altgriechischer und altägyptischer Erzichungslehren geprägt sind, ${ }^{30}$ denn im Gcgensatz zum Alten Ägypten, das ein fest umrissenes Erziehungsideal kennt, ${ }^{31}$ sind für das Altc Mesopotamien keine ausgesprochenen Erziehungslehren ${ }^{32}$ übcrliefert. Der intellektucllc Gesamtkontext Mesopotamiens würde eine derartiges Schrifttum auch nicht erwarten lassen. ${ }^{33}$ Immerhin zeigen aber einige Abschnitte der altbabylonisch-sumerischen Rangstreitliteratur und der Schulsatiren, ${ }^{3+}$ daß cs auch im Alten Mesopotamicn in Fragen der Erziehung zum Menschen sehr konkrete und offenbar auch einheitliche Vorstellungen gab, die die Erzieher ihren Kindern in der Praxis zu vermitteln suchten.

Um cin anerkanntes Mirglied cincr hierarchisch strukturierten Gescllschaft wie derjenigen der altbabylonischen Zeit zu werden, galt es nicht nur, seine

\footnotetext{
${ }^{29}$ Nichr diskutierc werden hier Methoden dor schulischen Didaktik, die einer separaten Untersuchung vorbchalten bleiben.

is Vel. etwa H. l. Marrou (wie Anm. 20), S. $2 \mathrm{ff}$.

3 H. Brunner (wie Anm. 16), S. 5; S. $116 \mathrm{ff}$. Ders., LÄ, Bd II, Sp. $25 f$.

32 Eine Zusammenfassung der wichtigsten ägyptischen Lehren bietet das LÄ, Bd. III, Sp. $964 \mathrm{ff}$. sub Lehren. Zur inhaltlichen Überschneidung ciniger altmesopotamischer Texte mit den Aussagen altägyptischer Lehren vgl. unten, Anm. 47.

3 Vgl. u. a. M. Civil, ABI II, S. 301 sub A.

3 In diesen Kontext gehören auch die sogenannten Examenstexce, die zwar nachaltbabylonisch überliefert sind, jedoch weitgehend auf altbabylonische 'Traditioner zurückgreifen.
} 
berufliche Ausbildung ${ }^{35}$ an den höchsten Leistungsmaßstäben zu orientieren, sondern eine Vielfalt von Verhaltensnormen kennenzulernen ${ }^{36}$ und einzuhalten, um den rechten Weg, an dessen Rand vielerlei Versuchungen standen, zu finden. Wie aber den Anvertrauten die richtige Ausbildung, wie die richtigen Erziehungswerte vermitteln, wo Worte oder Gesten allein oft versagen? Es bedarf also individueller didaktischer Mcthoden und auch disziplinarischer Mittel, um ein Kind, einen Lehrling oder den so gut dokumentierten Schreiberschüler seinem Ziel näherzubringen. Abgesehen von der spezifischen Wissensvermittlung für den Beruf des Schreibers, haben viele in den Edubba'a-Texten überlieferte Wertvorstellungen allgemeinc Gültigkeit. So fällt die auch durch den Überlieferungszufall bedingte scheinbare Einseitigkeit der Textüberlieferung nicht grundsätzlich ins Gewicht.

\section{1. $L o b$}

In denjenigen altbabylonischen Texten, die in irgendeiner Form die Ausbildung und Erziehung von Kindern bzw. Schülern zum Thema haben, ist sehr häufig von enträuschten und unzufriedenen Vätern und Pädagogen die Rede. Kritik, begründet in mangelndem Eifer und dem Verstoß gegen die vielfältigen Verhaltensregeln, scheint an der Tagesordnung. Wiederholter Tadel wird aber ganz offenbar als Ansporn zu besserer Leistung im Wettbewerb mit den Mitschülern verstanden. Sicherlich ist in diesen Darstellungen auch ein pädagogischer Ansatz erkennbar. Andererseits ist diesc scheinbar unverhältnismäßig negative Haltung auch gattungsbedingt: In der Rangstreitliteratur steht dem Selbstlob die Kritik am Kontrahenten gegenüber. In der Schulsatire Der Sohn des Tafelhauses fällt, entsprechend dem satirischen Charakter des Werkes, cin überschwengliches Lob erst, nachdem der Vater des Schülers sich gegenüber dem Lehrer, crkenntlich"

3s Zur Ausbildung in Alten Ägypten vgl. LÄ Bd. I, Sp. 569 ff., sowie F.. Feucht, Geburt, Kindheit, Jugend und Ausbildung (wic Anm. 17), S. 255 ff. mit Anm.").

3o In diesem Zusammenhang bcsonders aufschlußreich sind dic Vorschriften (Lehren?) eines ungcnannten Meisters (um-mi-a), dic cin Aufseher (ugula) einem angchenden Schreiber weitergeben möchte (Scbreiber und Aufseher, Z. 2-26; der Abschnitt endet in Z. 27 mit den Worten: níğ um-mia-ğ $u_{10}$ mu-un-pà-dè`-na) c-ra-šid nu-mu-ra-ab-taka ${ }^{2}$ Das, (was) mein Meister mir aufgezeigt hat, habe ich Dir nun aufgezählt; dabei wurde Dir nicht(s) ausgclassen“" (Text: TMHINF 337 9; drci weitere unpubl. Texce (MS M. Civil) geben die Varianten mu-pà-dè // 'mu-un'-[pà]-dè // mu-un-pàda). - Obwohl es sich aus dem "lext selbst nicht direkt ergibt, jst es mir wahrscheinlich, daß hicr nicht nur Verhältnisse des Schulmilicus reflektiert werden, sondern grundsätzliche Vertaaltens weisen eines Untergebenen gegenüber seinem Vorgesetzten (ugula) angesprochen sind. Jeder großere private, insbesondere aber die öffentlichen Haushalte verfügten im Rahmen ihrer Arbeitsorganisation über Aufseher. Neben den Anweisungen zum rechten Verhalten gegenüber einem Vorgesetzten spiclt, wie auch in anderen Edubba'a-Texten, u. a. die Erziehung zur Menschlichkeit eine zentrali Rollc. Auch im Alten Ägypten bestand neben der Fachlehre „ein wichtiger Teil der Grundausbildung aus Verhaltensanweisungen" (E. Fcucht (wie Anm, 18), S. 227). 
gezeigt hatte, ihn vom Edubba'a abholen ließ, ihm Bier ausschenkte, Öl über scine Schultern goß, ihn bekleidete und ihm einen Ring ansteckte, als „Geschenk“. So kann der vor seiner Beschenkung mit dem Schüler reichlich unzufriedene Lehrer attestieren: ${ }^{3 ?}$

„Junge, der Du gegen mein Wort kcine Abneigung hegrest, nicht faul warst, (Var.:) Junge, der Du mir gehorsam warst, mich zufrieden gestellt hast, der Du Dich den Anfängen der Schreibkunst angenähert (und sie) zu Ende gebracht hast, der Du Dich gegen nichts sperr(te)st, der Du (alles) in mcine Hand gegeben hast."

Im weiteren Kontext fügt der Lehrer hinzu:

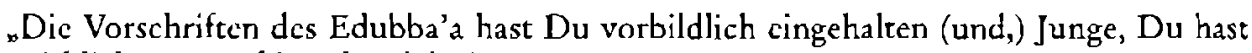
(wirklich) vernünftig gehandelt! ${ }^{k s 8}$

Immerhin verschweigt der Lehrer nicht, daß man ihm, um ein solch günstige Beurteilung des Schülers abgeben zu können, ,Geschenke' zukommen ließ, die die ihm üblicherweisc zustehende Vcrgütung bei weitem übertrafen. ${ }^{34}$

Sicherlich mag die obige Schilderung dic Realität ironisch überzeichnen, ebenso wie die Äußerung eines ständigen Nörgeleien ausgesetzten Sohncs:

"Niemals habe ich Lob aus einem Munde gchörr". to

Dennoch gehörten derlei Situationen ganz offenbar zum leidigen Alltag eines Kindes. Warum hätte man sich sonst in solch intensiver Weise mit dieser Problematik auscinandergesetzt? Andererseits konnte ein Schüler, der sich an die Vorschriften der Schulc hielt, fleißig arbeitete und den Vorgesetzten zu gefallen suchte, grundsätzlich mit der Anerkennung durch seine Lehrer rechnen. Dies wurde einem Schreibcrschüler schon frühzeitig von eincm, erfahrenen' Vorgesetzten nahegelegt: ${ }^{41}$

"Der Sobn des Tafelhauses, Z. 70-72 lû-tur inim-ğ $u_{10}$-šè gú li-bí-dù-a im-šub li-bí-ak (Var. (Texte I, P, CBS 10316, [unpubl., MS M. Civil]): [lú-t]ur inim-ğ $u_{10}-\check{s e ̀ ~ b a-t u s ̌-u ̀-n a m ~ s ̌ a ̀-g ̆ ~} u_{10} b i-d u_{12}-g a$ ) / nam-

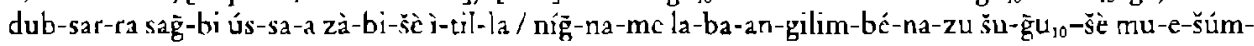
ma.

38 Ebd. Z. 89 á-áğ-ĝ́á-é-dub-ba-a pa bí-è lú-tur úmun bí-ak.

39 Ebd. Z. 73 níğ-ba á-kúšs(-a) diri mu-ni-in-ḡar-ra nam-dugud mu-e-dab-àm/-e „Der Iu (Vater des Schülers) cin Geschenk, dic cigentliche Arbeitslcistung übertreffend, ausgestcllt (und somit weitere) Anerkcnnung hin rugefügt hast".

"Der Vater und scin mißratener Sohn, Z. 117 a-rá-na-me-ka ka-tar-ra(-a) ka-ka ḡiš li-bí-(in-)tukuàm. Dic hicr gegebene Übersctzung folgt einem Vorschlag von C. Wilekc. Vgl. anders PSD A/1, S. 147 sub 1.3 "at no time you have ever listend to its praises" ; P. Atcinger, ÉLS, S. $570 \$ 564$ „Ceux qui en (du ,destin' fixé par Enlil) parlaient élogicusement/faisaient l'ćloge (topicalisê), tu ne les a jamais ćcoutés".

1 Schreiber und Aufseber, Z. 28 ğizzal bé bí-AK šà-šè gíd-i-dè sa $a_{b}$-ge-zu mu-da-an-g̃ál. 
„Du (Schüler)^2 sollst ihnen (den Vorschriften des Meisters) Aufmerksamkeit schenken; sie Dir zu Herzen zu nehmen - davon hängt Dein Wohlbefinden ab“.

Das zu erwartende Lob des Meisters konnte dann das folgende (zu oben fast wortgleiche) sein:

"Junge, der Du bei meinem (des Meisters) Wort wirklich dasaßest, mich zufrieden gestellt hast ${ }^{*}{ }^{+3}$

Lob und Anerkennung drückten sich aber auch in der Freude eines Lehrers über den Fleiß und die Demut eines Schülers aus:

"Meinen, großen Bruder' stimmte ich durch mein Arbcitspensum zufrieden.

Weil ich demütig war, freute or (der Meister) sich über mich (und) lobte mich"."4

So mögen die Kinder als Schiiler und Lehrlinge ihre Last damit gehabt haben, daß sie von klein an gemaßregelt wurden und unter der Aufsicht der Erwachsenen standen. ${ }^{45}$ Erfüllten sie jedoch deren Erwartungen, so ließ man es an Lob und Anerkennung durchaus nicht fehlen.

\section{Vorbild}

In welchem Umfang mesopotamische, zumindest altbabylonische Eltern und Pädagogen von der Möglichkeit Gebrauch machten, Vorbilder vor ihre Kinder zu stellen, läßt sich nach den überlicferten Texten nicht abschließend bcurtcilen. Die Heroen der epischen Literatur, mit denen fortgeschrittene Schreiberschüler in mündlicher wic schriftlicher, anderc Personenkreise nur in mündlicher Form konfronticrt waren, dürften als solche gedient haben, ebenso wic die in ausladenden Hymnen dargestellten Könige der Ur-III-Zeit, dic recht unterschicdliche Charaktertypen abgaben."6

Nie hören wir etwas von einem spezifischen und allgerneingültigen Ideal, auf

\footnotetext{
${ }^{42}$ Im fortlaufenden Texc (Z. 29) als dub-sar úmun-ak "Schreiber, der vernünftig handelt" bezeschnet.

4) Ebd. Z. 61 lú-tur inim- $\bar{g} u_{10}-$ šc̀ ba-tuš-ù-nam šà- $\bar{g} u_{1 c}$ bí- $d u_{1 c}-$ ga-àm (Lcsung der Verbalform batuš-ù-nam nach 2 unveröff. 'Texten, MS M. Civil; Var.: ba-e-tuś-ù-nam (unveröff.); ba-tuš- 'ù' (SRT' 27 Vs. 13); ba-tuš-un(-)nam-mu (SI.TNi 114 ii 37, Fchler?).

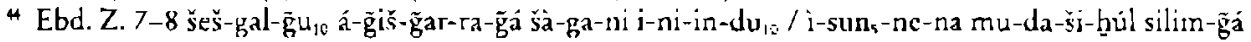
i-ni-in-du $1 ;$;.u Z. 8 vgli. unten, Anm. 102.

45 Ein schr beredtes Zeugnis liefert hierfür Schreiber und Aufse'ber, Z. $50-51$ tur-ra-gu

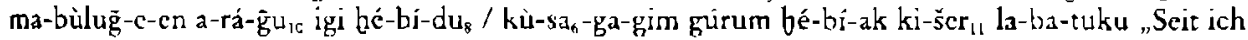
klein war, hast $\mathrm{L}$ (u mich großgezogen, hast meinen Lebonswandel beobachtct, hast ihn wie schöncs Silber geläutert. (Dabei) kanntest I) keine Grenzc". Vgl. w diesen Zcilen M. Civil, JCS 20 (1966), S. 123.

46 Vgl. S. Tinney, OLZ 90 (1995), Sp. 8.
} 
das hin ein Kind erzogen werden solltc. ${ }^{47}$ Dic crsten und zunächst wichrigsten Vorbilder im Leben eines Kindes boten auf natürliche Weise die Eltern. Es galt:

„Das (ist es), was Enlil den Menschen (zum) Schicksal bescimmt har: Der Sohn folgr dem (Lebens-) Werk's scines Vaters"."

Nicht alle Kinder konnten sich aber mit dicser Vorgabe, mit der Person und dem Lebenswerk ihres Vaters abfinden. So erklärt der Sohn in der Schulsatire Der Vater und sein mißratener Sobn:

"Sollee ich vielleicht die Stellung meines Vaters anstreben? ${ }^{\text {us }}$

Angesichts dieser Aussage ist die Enttäuschung dieses Vaters über seinen Sohn durchaus verständlich:

"Von dem, was ich getan habc, ${ }^{51}$ hast Du überhaupt nichts gelernc ${ }^{a .2}$

Ob jener Sohn etwa nichts von den berühmten, scit alters überlieferten Ratschlägen des Šuruppag an seinen Sohn Ziusudra gehört, oder sie nicht beherzigt hatte? Aus diesem Kompendium hätte er nämlich wissen müssen:

„Der Vater ist [wie] ein Gotr; er läßt [...] crstrahlen.

Der Vater ist (wie) ein Gort; sein Wort ist das rechte.

Der Ratschlag des Vaters will beachtet werden! “5,3

" Diese Beobachtung steht in engem Zusammenhang mit der Tatsache, daß das literarische Genre der ,Lehren" nach der schriftlichen Überlieferung Mesopotamicns im Vergleich zum Alren Ägypten weniger produktiv ist. Formal deutlich unterschieden (zur Definition altägyptischer Lehren vil. das LÄ, Bd. III, Sp. 964), weisen jedoch altmesopotamische Tcxtc wic dic ,Unterweisungen des Suruppay an seinen Sobn Ziusudra' (s. Rl $\Lambda$ 7, S. 45 d)), die von der Mitte des 3. Jahrcausends bis in die neuassyrische 7,eit überliefert sind, ebenso wie die schon früh in der Schule cingesetzten Sprichwortsammlungen und die sog., Counsels of Wisdom' cine enge Verwandeschaft zu Altägyptischen Lehren aut.

* Mit dieser Übersetæung von kíğ-gi -a soll ausgedrückr werden, daß nicht nur der Beruf des Vaters, sondern auch die Frfüllung seiner Funkrion und Rollc in Familic und Gcsellschaft in die Schicksalsentscheidung Frlils einbe'zogen ist.

" Der Vater und sein mißratener Sobn, Z. 115-116 nam den-lil-le lú-u 18 -lu nam-bi tar-ra / dumu kíğgì-a-ad-da-na-ka i-ib-ús.

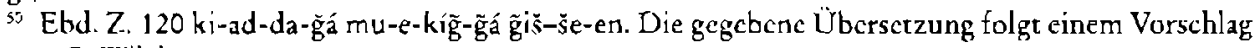
von C. Wilcke.

"Hinter dieser Aussage steht die Vorstellung des Vaters, scin Sohn solle es ihm gleichtun. Dies findet eine interessante l'arallele in der ägypuischen, Lehre cincs Mannes an seinen Sohn' (mittleres Reich), in der ein Vater seinen Sohn auffordert: "Mache es wic ich" (vgl. H. Brunner (wie Anm. 16), S. 64; S. 161 Qu. XVII. Weitere Literatur zu diesem 'lext bictet LÄ, Bd. III, Sp. 984-986).

"Der Vater in sein mißratener Sobn, Z. 146 níg bí-in-ak-ğ $\mathbf{u}_{10}$ ba-ra-zu.

5. Unterzeisungen des Šuruppag, Z. 261-263: [a]b-ba diğir(-ra)-àlm (x)] mu-un-zal-zala-ge / ab-ba diğir-à $[m$ i]nim-ma-ni zi-da / na-ri ab-ba-šè ḡizzal [hé-c]m-ši-ia-AK; vgl. B. Alster, Sumerian Proverbs, 5. 137; C. Wilcke, ZA 68 (1978), S. 261. 
Neben Vater und Mutter ${ }^{54}$ wurden den Kindern stets auch (erfolgreiche) Geschwister, Kameraden und Schulkollegen vor Augen gehalten: ${ }^{53}$

"Auf Deine Genossen schaust Du nicht, wenn ihr als Gespann ${ }^{56}$ hintrctcr.

Auf Deinen Ireund, Deinen Gefährten schaust Du nicht. Warum tust Du es (ihm) nicht gleich?

Nein! Deinen älteren Brüdern tu es gleich!

Nein! Deinen jüngeren Brüdern tu es gleich!“

Daß es sich bci dicsen Aussagen nicht nur um literarische Wendungen oder gar litararische Fiktionen handelt, bewcist nicht zuletzt die Literatur des Alltags. Enträuscht vom geringen Impetus und dem mangclnden 1)urchsetzungsvermögen seines in Mari residierenden Sohnes Jasmab-Addu, schreibt der altassyrische König Šamši-Addu unter Hinweis auf den erfolgreichen und in Konkurrenz zu Jasmah̆-Addu stehenden Bruder Išme-Dagān:

„Wie lange noch sollen wir Dich immer wieder anleiten?

Bist Du immer noch kindisch, bist Du kein Mann?

Hast Du noch immer keinen Bart auf Deinen Wangen?

Wie lange noch kannst Du Deinen eigenen Hausstand nicht führen?

Siehst Du nicht Deinen Bruder, der schon große Armecn anführt?" "57

Noch nachdrücklicher wird Šamši-Addu in einem anderen Bricf an JasmahAddu: ${ }^{58}$

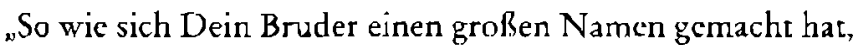
genauso mach auch Du Dir in Deinem Land cinen großen Namen!“‘s

\footnotetext{
` Neben dem Ratschlag des Vaters galt, wenngleich nuancicrt, auch das Wort der Mutrer gleich dem eines Gottes inim-ama-ru-gim ${ }^{(s i c)}$ inim-diğir-[zu]-gim ḡizzal hé-em-řs-AK "Das Wort Deiner! Muttcr sollst Du beachten wie das [Deines'] (Schutz-) Gottcs" (VS 10204 vi 1; zur Rekonstruktion der Tafel und weiterer Literatur vgl. M. Civil, OrNS 41 (1972), S. 88-89). Eine parallele Aussage bietet Unterweisungen des Suruppag, Z. 259.

5s Der Vater und sein mißratener Sohn, 7. 102-106: lú-tab-ba-zu lú ğ̣̌šsudun-dili-a / i-sus-ge-en-zana igi nu-mu-ni-du - -ru-un / a-na-1š nu-mu-ni-îb-sè-ge-en / ku-li-zu du ${ }_{10}-\mathbf{s a - z u ~ i g i ~ n u - m u - n i - d u ~}$ ru-un a-na-aš nu-mu-ni-îb-sč-gc-en / in-nu šeš-gal-zu-ne sè-ke-nc-cb / in-nu šeš-bàn-da-zu-ne sèke-ne-eb.

so Zur Deutung dicser Formulierung vgl. C. Wilcke, ZANF 25 (1969), S. 84, Anm. 79 und Ả. Sjöberg, JCS 25 (1973), S. 127.

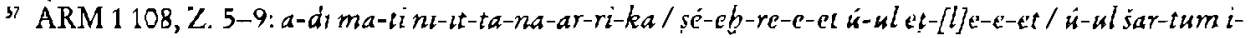

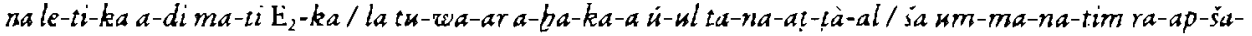
tim ḱ-wa-a-ru. Vgl. ähnlich ARM 1 73, 7. 42-47; ARM 1 61,Z. 10-12; hier (Z. 12) erfatiren wir auch, daß Jasmah-Addu, gleich dem Sohn in $I$ er Vater und sein mißßratener Sohn durchaus kein Kleinkind mehr war und bercits nin der Fülle (seiner Jahre)" ( $(-n a l a-l e-k a)$ stand.

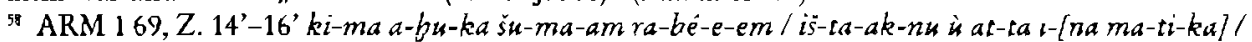
š-ma-am ra-bé-e-e/m/ši-lıt-ka-an].

59 Durchaus pikant und sehr ironisch formuliert ist dic Vorgeschichte dieser Aufforderung ŠamšiAddus gegenüber Jasmah- $\Lambda$ ddu, es seinem Bruder Išme-Dagān gleich»utun: "Frseu Dich! Dcin
} 
Nur sehr wenig erfahren wir in unseren Texten darüber, mit welchen Methoden man Mädchen zu crziehen suchte. Dieser Befund ist eng verknüpft mit der Tatsache, daß die Existenz von Schreiberinnen zwar bezeugt ist, ${ }^{60}$ jedoch eher die Ausnahme war. So enthalten die das Schulmilieu schildernden Texten keine Aussagen über weibliche Auszubildende, ihre Situation und Position gegenüber den Schuloberen. Vermutlich hatten sie in dicsem Bercich den glcichen Ansprüchen zu genügen wie ihre männlichen Kollegen. ${ }^{61}$

\section{Wettbewerb}

Kaum ein Lehrer und Erzieher dürfte jemals darauf verzichtet haben, seine Schüler, Lehrlinge, Söhne oder Töchter dadurch anzuspornen, daß er ihnen andcre, erfolgreichere Schüler odcr Geschwister vorgehalten hätte. Nur zu selten erfahren wir jcdoch erwas über das Endergebnis, sprich den Erfolg solcher Motivationsversuche. Mcist werden wir nur mit dem Wunsch eines Erwachsenen nach besserer oder bester Leistung seines Zöglings konfrontiert, so ctwa in der ,Schulsatirc' Der Sohn des Tafelhauses:

„Deiner Brüder Anführer seist Du!

Deiner Gefährten $\Lambda$ llerbester seist Du!

Der alles übcrragende Edubba’a-Schüler seist Du!"‘2

Bruder (Išmedagān) hat hier gesiegc, aber 1)u liegst mitten unter den Frauen" (ARM 1 69, Z. 8'-11' In-u ba-de-et a-b̧u-ka an-ni-ki-a-am / da-aw-da-am i-du-uk is at-la / aš-ra-nu-um l-na bi-ri-it MUNUS.MEŠ / sa-al-la-at).

do Vgl. Ă. Sjöberg, $\Lambda$ S 20, S. 177 mir Anm. 66; FI. Wacczoldt, Das Schreiberwesen in Mesopotamien (unveröff. Habil.-Schrift, Heidelberg 1974), S. 15 f.; R. Harris, The Female oSage" in Mesopotamian Lircrature, in: J. G. Gammic u. L. G. Pcrdue (eds.), The Sage in Israel and the Ancient Near East (Winona Lakc 1990), S. 5 ff.); als Schreibcrin bekannt ist Ninšatapada, Tuchter Sînkāšids von Uruk (vgl. W. W. Hallo, FS Garclli; S. 377 ff.); im altbabylonischen Sippar läß sich sogar eine Schrciberin nachweisen, dic ihre Ausbildung vermutlich bei ihrem Vater erhicle, der ebenfalls Schreiber war, vgl. R. Harris, Ancicnt Sippar, S. 288 mit Anm. 132; in Mari finden sich Schreiberinnen im Gefolge von Prinzessinnen, vgl. J.-M. Durand, M.A.R.I. 3, S. 167-169 mir Anm. 41.

o1 Grundsatzlich schien aber die ursprüngliche und cigentliche Bescimmung der Töchter gewesen zu scin, der Mutter als Vorbild nachzufolgen und Kinder zu gebären. Mit diesem Vorbild war sie üblicherweise so lange konfrontiert, bis sic selbst in den Haushalc eines Manncs zog und die Roile einer Murter übcrnahm: „Dic Mutter isc (wie) der Sonnengott (Utu): Sie gebicrt Menschen“ (ama

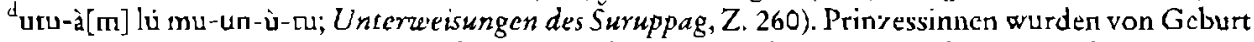
an von ihren Ammen umsorgt, die ihnen bisweilen sogar in den Haushalt ihres zukünftigen Gatten folgten (vgl. AEM J/2, Nr. 298; B. Lion, GS Birot, S. 228, Anm. 12 mit weitcrer Literatur). Bci der Vermittlung von Werten und Kenntnissen an die Prin\%essinnen dürfte den Ammen der Herrscherhäuser somit erhebliche Bedeutung zukommen.

az Der Sobn des Tafclhauses, Z. 77-78: šcš-zu-ù-ne IGI.DU-bi bé-me-en / dù, bi hać-me-en / an-ta-ğál-dumu-é-dub-ba-a-ke -ne haé-me-en. Vgl. zu diesen Zeilen C. Wílcke. ZANF 25 (1969), S. 92, Anm. 92. 
Sind diese Worte eines Lehrers an einen seiner Schüler gerichtet, so konnte cin Vater das Ziel allen Strebens seines Sohnes durchaus noch anspruchsvoller formulieren:

"(Unter) den Gelehrten Deiner Stadt sollst Du der beste sein!"6.

Das Wetrbewerbsdenken als pädagogischer Leirgedanke drückt sich im Bcreich der Schule besonders in einer Reihe von Streitgesprächen aus, die Aufschluß über das ausgeprägte Konkurrenzdenken der Schüler untereinander, aber auch gegenüber ihren älteren ,Kollegen' geben. Die Absicht der Pädagogen, vermutlich der Meister (um-mi-a), die hinter der Konfrontation der Schüler mit diesem Genre steckte, war sicherlich recht vielschichtig. Zum einen konnte aufgrund der Dialogform - im Gegensatz zu fast allen anderen in der Schule behandelten Textgruppen - Umgangssprache eingeübt ${ }^{64}$ und Verhältnisse des schulischen wic des täglichen Lebens reflektiert werden.$^{65}$ Daneben konnten die Pädagogen über diese Texte auch soziale Normen vermitteln, deren Kenntnis und Verwirklichung als Voraussetzung des individuellen Erfolges angesehen wurden. Vermutlich galt es auch für die Schreiberschüler, sich mit Blick auf ihre spezifischen beruflichen Perspektiven an der Argumentationssicherheit der vorgestellten Kontrahenten zu messen und diesen nachzueifern. ${ }^{66}$

Im Wettbewerb der Kontrahenten galt derjenige als Sieger, der den Mitschüler verbatim übertraf und am Ende den, Schicdsrichter' auf seine Seite ziehen konnte. Bei den vorgebrachten Argumenten schien, zumindest nach unserem heurigen Eindruck, kein Niveau zu niedrig, ja für cinen Schüler bisweilen eher unpassend, "7 um nicht vorgebracht zu werden. Eine Grundhaltung war: ,Ich kann und weiß alles besser als $\mathrm{Du}^{6}{ }^{68}$ Schon die elementarsten Fähigkeiten und Kenntnisse des Kontrahenten wurden in Zweifel gezogen:

\footnotetext{
${ }^{6}$ Der Vater und sein mißratener Sabn Z. 178 lú-úmun uru-za sağ hé-me-en.

- Diese $\Lambda$ bsicht ist wohl nicht zu gering zu schätzen in einer Zeit, in der das Sumerische keine Umgangssprache mehr war, sondern nur noch Kultur- un Amtssprache. Eın (ein-)gebildeter Schreiber konnte dann von sich behaupten, er beherrsche die sumerische Konversation.

*s Ähnliche Intentionen verfolgten die humanistischen Dialogschreiber mit ihren lateinischen Schilergesprächen, vgl. A. Bömer, Die lareinischen Schülergespräche der Humanisten 1, S. 5.

"In diesem Zusammenhang ist besonders an die Streitfähigkeit und Wortgewandtheit eines Schreibers (Advokaten) vor Gericht zu denken, vgl. hierzu C. Wilcke, Schrift und Schriftlichkeit, S. 497 sub 4.4.1.

* Vgl. etwa die teilweise in der Fäkalsprache und in Tiervergleichen gehaltenen Schimpfkanonaden in Strett zweter Schulabsolventen, Z. $10 \mathrm{ff}$.; für Z. 14-21 s. B. Alster, FS Loskkegaard, S. 9 mit Anm. 22. Auch unter den Schülergesprächen der Humanisten finden sich gelegenclich Themen, die für Heranwachsende nicht unbedingt geeignet erschienen, vgl. A. Bömer, Die lateinischen Schülergespräche der Humanisten 1, S. 5.

"Vgl. Streit zweier Schulabsolventen, Z. 7-8 inim-inim-ma nam-dumu-é-dub-ba-a-kea-ne/ga-abšid-dè-en diri-zu-šè ì-zu „Alle Themenbereiche des Schreiberschülertums will ich Dir aufzählcn. Ich kenne sie (nämlich) viel besser als Du“". Vgl. zu diesen Zeilen, A. Sjöberg, AS 20, S. 164 mit Anm. 18, der jedoch inim-inim-ma als nthe whole vocabulary" interpretiert.
} 


\section{Konrad Volk}

„Einc Tafel kannst Du nicht formen, cine einkolumnige Tafel nicht kncten.

Deinen eigenen Namen ${ }^{69}$ kannst Du nicht schreiben, der Ton ist für Deine Hand völlig ungeeignet.

Wenn Du Dich hingestellt hast, um mit der Hacke arbeiten, dann isc Dir dic Hacke bestimmt schon hingefallon!" 70

Auf spezifische Unkenntnis von Lehrstoff aus der Grundstufe wird in dem Streitgespräch zwischen dem Schülcr Enkimansum und seinem ,großen Bruder Girini' isa angespie!t: ${ }^{71}$

„Du schriebst eine Tafel. Erwas Sinnvolles ist daraus nicht geworden. ${ }^{72}$

Einen Brief schricbst Du. Das ist alles was Du kannst.

Ausgegangen, um einen Flausbesitz ${ }^{73}$ aufzutcilen, kannst Du nicht (einmal) den Hausbesitz auftcilen.

Ausgegangen, um cin Feld abzuteilen, ${ }^{74}$ kannst Du nicht (einmal) Meßleine und Maßstab halten,

den Pflock für die Feld(vermcssung) kannst Du nicht setzen. Scine Zweckbestimmung erkennst Du (nämlich) nicht ${ }^{*}$.

Eine ähnliche Einschätzung seines Gegenübers gibt ein Schreibcr im Streit zweier Schulabsolventen:

„Hast Du eincn Prozeß eröffnct, führst Du ihn hinterher nicht zu Ende.

Deine Hand kommt Deincm Mundwerk nicht gleich"."s

${ }^{69}$ mu ní-za nu-e-da-sar-re könnte auch gedeutet werden als "von Dir selbst aus kannst Du keine cinzige Zeile schreiben".

7o Enkimansum und Cirini isa, Z. 63-65 dub ru-mu-e-da-dím-en ${ }^{\text {Im) }} \mathrm{i}-\mathrm{gi} \mathrm{i}_{4}$-in šu nu-e-da-ra-ra-an / mu ní-za nu-e-da-sar-re im šu-za nu-ub-du, / al AK-dè gub-ba al šub bé-da-ğál. Für Z. 63-64 vgl. dic Partiturumschrift von W. H. Ph. Römer, UF 20 (1988), S. 237.

"Ebd. Z. 19-23 dub i-sar dím-ma nu-mu-da-an-ku, / ù-na-a-du e-dè gèn-na é nu-mu-da-ba-c-en / a-šà si-gc-dè gen-na éš-gána gi 1-ninda nu-mu-da-ha-za / ḡis gag ašà nu-e-da-rú-en dím-ma nu-mu-e-da-ran-ku, ' (UET VI 150, Vs. 19-23). Vgl. zu ciner Partitururnschrift der Zeilen W. H. Ph. Rümer, UF 20 (1988), S. 237.

"1 Bci der gegebenen Übersetzung folge ich einem Vorschlag von C. Wilcke.

7 Sowohl A. Sjöberg, AS 20. S. 168 mir Anm. 34; ders. PSD B, S. 6 sub 5.2 sowic W. H. Ph. Römer, UF 20 (1988), S. 237 lescn den Zeilenanfang gána "Feld“. Ein Zeichenvergleich des ersten Zeichens der Zcile (UET VI/2 150, Vs. 21) mit dem 9. Zeichen der Folgezeile (UET VI/2 150, Vs. 22), wo eindeutig gána vorliegt, zeigr deutlich, daß an der vorlicgenden, wie an den entsprechenden parallelen Stellen des Textes ć, nicht gána zu lesen ist.

" a-šà--si(-g) bedeutet wörtlich „ein Feld cintiefen“. Gemeint ist damit, daß Pflöckc ( ${ }^{\bar{F}}{ }^{\circ}$ gag, vgl. die folgende Textzeile) an den Eckpunkten des mit Meßleine oder Maßstab zu vermessenden Feldes eingeschlagen werden. Im übertragenen Sinne ergibe sich daraus die Überscezung „ein Feld abteilen".

75 Streit zweier Schulabsolventen, Z. 52-53 di i-du ub-da-sá (CT 4247 ii 8-9; SLTNi 116 Vs. 1-2; Ni 9715 (ISET 2 84) Rs. 12 (nur Z. 52); zu Z. 52 vgl. A. Sjöberg, AS 20, S. 165). Nach SP 2.40 galt grundsätzlich nur derjenige Schreiber als kompetent, dessen Hand mit seinem Mund gleichkam: dub-sar šu ka-ta sá-a e-ne-àm dub-sar-ra-àm „Ein Schrcibcr, (dessen) Hand (scinem) Mund glcichkommt, der ist cin wahrer Schreibcr". 
Derlei Konkurrenzdenken war nun keineswegs auf das männliche Geschlecht beschränkt, wie der Spott einer Konkurrentin aus dem Streit zweier Frauen (B) zeigt:

„Wolle kann sie nicht zupfen, mit der Spindel kann sie nicht spinnen. ${ }^{76}$

Dic Hand taugt für dic Arbeit nicht. Beim ,Eintreten' und ,Herausgehen' ist sie säumig". ${ }^{77}$

Neben handwerklich-technischen Fähigkeiten, die ein Mädchen schon von ihrer Mutter vermittelt bekam und gegebenfalls in einem Betrieb, der Frauen beschäftigte, zur weiteren Anwendung brachte, ${ }^{78} \mathrm{maß}$ die altbabylonische Gesellschaft dem äußeren Erscheinungsbild wie auch den intellektuellen Fähigkeiten einer Frau erheblichen Stellenwert bei. Diese Eigenschaften wurden wiederholt zueinander in Bezichung gesetzt und waren unter Frauen Zielscheibe heftiger Kritik: ${ }^{79}$

„Wer Dein Handeln nicht kannte, sah Deine hohe Erscheinung, sah Dein schönes Antlitz.

,Ein (wahrer) Mensch ist sie' sagt er.

Du aber, (in Wirklichkeir) ist Dein Verstand der eines Affen,

Deine Erkenntnisfähigkeit ist (nichts als) die Erkenntnisfähigkeit eines Hundes".

Diese noch milden und allgemeinen Anschuldigungen gegenüber einer Kontrahentin konnten komplementiert werden durch ganz spezifische Frauenthemen: ${ }^{80}$

„Anstifterin, die Männer der Stadt betrügend, die jungen Frauen, die in der Nachbarschaft leben, können ihretwegen nicht schlafen“.

So schwerwiegend diese Vorhaltungen bereits erscheinen, sie waren noch weirer steigerungsfähig;

\footnotetext{
76 Diese negative Aussage erinnert an das akrostische "Gedicht auf die tuchtige Frau" (Proverbia 31:10ff.), in dem die tüchtige Frau beschrieben wird als "Sie sieht sich um nach Wolle und Flachs, und was ihren Händen gefällt, schafft sie an" ... ,Ihre Arme strecks sie nach dem Spinnstock, und die Hände halten die Spindel“ (Proverbia 31:13 und 19).

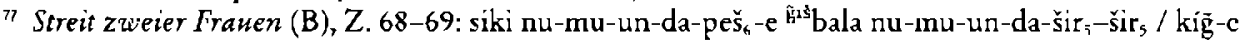
šu nu-mu-un-da-sá ku+-ku, è-dè ab-lá (CBS 14174+UM 29-13-1 [unpubl., MS M. Civil]). Dic Z. 6869 dieses Textes werden in Z. 67 verallgemeinernd eingeleitet mit den Worten na-áḡ-nu-nuz-c la-badu, „Für Frauenangelegenheiten ist sie ungeeignet“.

78 Zur Mädchenarbeit im Alten Ägypten vgl. E. Feucht (wie Anm, 18), S. $336 \mathrm{ff.}$

$"$ NBC 7805, Vs. 25-30 (unveröffentlichtes MS von A. Cavigneaux) lú nî்̃-ak-zu nu-un-zu-a / alansukud-da-zu igi i-ni-in-bar/'mùšl-me-sa -ga-zu igi i-ni-in-bar/ lú-àm íb-bé / za-e dím-ma-zu dímma ugu ${ }^{\text {ugu4 }}-b[i] /$ malya-zu malga-ur-gi $i_{7}-\Gamma^{\Gamma}{ }^{\Gamma} x^{\top}[(x)]$.

Streit zqueier Frauen (B), Z. 129-130 bún-du ${ }_{11}-\mathrm{du}_{11}$ [ğ]uruš-uru-ka lul sè-sè-ke / ki-sikil-tur daggi,-a ti-la ù nu-mu-un-ši-ku-ku (UET VI/2 157, Vs. 2 -3 mit unveröff. Dupl. (MS M. Civil)). Zu Z. 129-130 vgl. PSD B, S. 181 f.; zu Z. 130 s. B. Alster, FS Lakkegaard, S. 8, Anm. 6.
} 
„Negerin aus Mclubba, Schwachsinnige, schlechtes Mehl ${ }^{* 81}$...

"Hintcrn, dessen After kränklich" ist, kleine Scham mit langen Schamhaaren “ ${ }^{82}$

Beide Geschlechter, dies zeigen uns dic Texte aus der Überlieferung der altbabylonischen Schule, wurden in Mesopotamien sowohl in häuslicher wic schulischer Erziehung schon frühzcitig mit dem Wettbewerb innerhalb der eigenen Geschlechtsgruppe konfrontient und hierüber wohl auch motiviert. ${ }^{83}$ Galt es bei den Jungen, dic besten schulischen Leistungen zu erbringen, um im beruflichen Wettbewerb vorne zu stehen, so scheint das Thema berufliche Bildung ${ }^{k 4}$ im Wettbewerb der Mädchen und Frauen eine eher untergeordnete Rolle gespielt zu haben. Ziel allen Strebens und Konkurrenzdenkens schcint für beide Geschlechter das Erreichen cines möglichst hohen Sozialprestiges gewesen zu sein.

\section{Lockung mit gesellschaftlicher Anerkennung und mit Woblstand}

Auf manchen Schüler mögen Hinweise auf das große Vorbild des Vaters oder älteren Bruders, auf erfolgreichere Mitschüler, Ermahnungen oder gar Schläge nur wenig motivierend gewirkt haben. Die Schulsatire Der Vater und sein mißratener Sobn zeichnet ein lebendiges Bild einer solchen Situation. Der von seinem Sohn maßlos enträuschtc Vater, selbst arrivierter Schreiber, der dafür sorgte, daß sein Sohn niemals schwere körperliche Arbeiten ausführen mußte, ${ }^{85}$ der alles versucht hatte, seinen Sohn auf dic rechtc Bahn zu bringen, ${ }^{86}$ wünscht

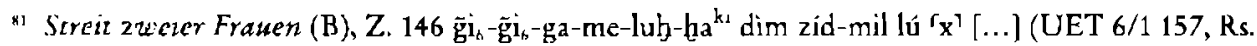
19; CBS 10211+N 34545 (unpubl., MS M. Civil); vgl. zu dieser Zcile B. Alster, FS Lakkegaard, S. 8, Anm. 19.

k2 Streit zweier Frauen (B), Z. 149 dúr gu-du-bi zára gal,-la-tur síg gal -la gíd-gid (UET 6/1 157, Rs. 20; CBS $10211+\mathrm{N} 34545$ [unpubl., MS M. Civil]).

"s Im historisch-gcographischen Zusammenhang gilt es zu anzumerken, daß der Wettbewerb als Ansporn zu größerer Leistung nach H. Brunner (wie Anm. 16), S. 57, im Alten Ägypten gegenüber den anderen Erziehungsmitteln zurücktritt. Wie tief der Wetrbewerbsgedankc jedoch im altägyptischen Denken verwurzelt ist und sich nicht nur im sportlich-achletischen Wertbewerb ausdrückt, stellt W. Decker, Sport und Spiel im Alten Ägypren, S. $112 \mathrm{ff}$., dar. Im Griechenland der älteren Zeir wird der "stete Eifer des Sichaneinandermessens" (vgl. W. Jaeger, Paidcia, S. 29) in der viclziricrten Zeile 208 des sechsten Gesanges der llias "Immer der erste zu sein und vorzustreben vor anderen" treffend zusammengefasst und läßt sich, herausgelost aus seinem kulurgeschichtlichen Zusammenhang, durchaus auf das Denken der Mesopotamier zu Beginn des. 2. Jahrtausends übertragen.

${ }^{84}$ Damit ist spcziell der Bereich der schulischen Ausbildung angesprochen, vgl. hierzu $\mathrm{H}$. Waetzoldt, Das Schreiberwesen in Mesopotamien (wie Anm. 60), S. $15 \mathrm{f}$. Davon unberihrt ist dic handwerklich-technische Ausbildung, die mit der Vermittlung von Kenntnissen durch dic Mutter (bei Prinzessinnen die Amme) beginnt. Unklar ist, ob ein Mädchen bzw. cinc junge Frau die notwendigen Kenntnisse im Umgang mit geschäftlichen und juristischen Angelegenheiten von Mutter oder Vater vermittelt bekam.

"s Der Vater und sein mißratener Sobn, Z. 74-83.

${ }^{\text {ac }}$ Ebd. Z. 98 a-ba-àm e-ne lú diri-g̃u $u_{10}$-š̀ dumu-ni-ir in-na-an-kúš-a „Wer ist derjenige, der sich mehr als ich um scinen Sohn bemüht hat?"
} 
ihm trotz. seiner Unzufriedenheit zum Abschluß, er möge vor seinem Gott Gefallen finden, cin wahrer Mensch, der beste Gelehrte der Stadt werden, und: „In Deiner Stadt, d(ies)em schönen Ort, soll man Deinen Namen (rühmend) aussprechen" ${ }^{87}$ Demnach hofft der Vater, die Perspektive des Sohnes auf gesellschaftliche Anerkennung, die einen erfolgreichen Schreiber erwarten konnte, möge als Anreiz zu größerem Eifer wirken.

Natürlich wußten die Pädagogen als Redaktoren der in der Schule tradierten Schulstreitgespräche schr genau um die Wirkung der Perspektive auf gesellschaftliche Anerkennung und auf Wohlstand. Deshalb ließen sie ihre Protagonisten in den Dialogen sich gegenseitig in drastischer schwarz-weiß-Malerei positive und negative Größen gesellschaftlicher Werte entgegenhalten. ${ }^{88}$ Erstrebenswerte Perspektiven wurden oft über die Abgrenzung gegenüber gesellschaftlich unterprivilegierten und diskriminierten Personen oder Gruppen der Gesellschaft vermittelt. Mit Faulheit, Unpünktlichkeit, Schlamperei, Flucht von der Arbeit, Überheblichkeit oder Schuldenmacherei konnte man weder zu Reichtum noch Anerkennung kommen. Man drohte zum Gespött der Gesellschaft zu werden, der Schuldhaft, Sklaverei, Armut und Wohnsitzlosigkeit zu verfallen. Wer jedoch den rechten Weg verfolgte, sich durch Pünktlichkeit, Fleiß, Bildung, Anstand und Menschlichkeit hervortat, konnte Ansehen erwerben. Eine bürgerliche Abstammung (nam-dumu-lú) galt in diesem Zusammenhang als gegebenes gesellschaftliches Kapital, das man jedoch leicht verspielen konnte, wie dic Sorgen des oben genannten Vaters um scinen Sohn zeigen. Um Anerkennung zu gewinnen, war außerdem nicht nur die einzelne Person, sondern der gesamte familiäre Kontext von Bedeutung. Glücklich schätzen konnte sich, wcr sagen konnte: ${ }^{89}$

"Meine Mutter ist eine kluge I'rau, die das (Stamm-) Haus aufgebaut hat.

Von den Mägden ${ }^{90}$ stchen 10 vor ihr."

Mein Vater ist Gencral (und) Richter beim König.

Meinc Brüder sind „Gendarme" des Königs. Aufscher über 50 (Leute) sind sic.

Mcine Schwestern stehen wie ein Türflügcl im fest gegründeten Frauengemach“, $9 z$

"Ebd. Z. 179 uru-zu ki-sa -ga mu-zu bé-pà-dè.

* Vgl. hicrzu dic Intenrionen der mittelalterlichen Dialogschreiber, die einerseits ihre Schülcr lenken, andererseits mit den gegebenen Inhalten ihren eigenen Ansichten Ausdruck verleihen wollten, vgl. A. Bömer, Die lateinischen Schülergespräche der Humanisten 1, S. 5.

"Enkitalu und Enkibeg̃âl, 7. 178-182 (TMHNF 342 iii 21-25; STVC 133, Vs.' in 1'-5'; UET 6/2 153, Rs. 34-37) ama-ğu $u_{1 \jmath}$ bur-š̌u-ma lú-é-dù-a-ka (Var. UEI 6/2 153, R.s. 34: -kam) / géme-ta 10-àm igi-ni-šè al-sus-ge-cš / ad-da-g̃u, sagina di-ku;-lugal-a-kam (Var. UET 6/2 153, Rs. 36: lu]gai-ld-

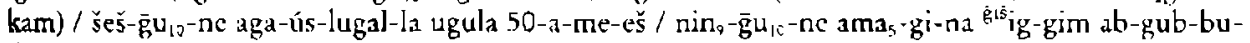
dèr-ě̀. Vgl. zu den Zcilen 180-182 bereits A. Falkenstein, NG 1, S. 266.

9: Zur Lesung géme-ta (TMHNF 342 iii 22) vgl. C. Wilckc, Kollationen, 5.38 ad iii 22, 1-8.

${ }^{91}$ Diesc Zahlenangabe verweist eindeutig auf cinen Haushalt der gehobenen Schicht. Zum Vergleich: Dic nidirtum „Mitgift" der Prinzessin Sìmātum aus Mari beinhalset neben cincr grolien Anzahl von Luxusgegenständen ebenfalls 10 Diencrinnen (vgl. B. I.afont, CRRA XXXlll, S. 118).

92 Die Interpretation der 7eile ist nicht ganz unproblematisch, da die Verbalform wic obcn, 
Wie immer die Wirklichkeit hinter einer soichen Aussage ausgesehen haben mag, ${ }^{93}$ die Aussicht cines Schreiberschülers auf Wohlstand ${ }^{14}$ mag so manchen vcranlasst haben, über das schwerc Los des Alltags ${ }^{95}$ hinwegzusehen: „Hast Du Dich der Schreibkunst (ordentlich) zugewandt, dann wird (akk.: soll) sie Dir Reichrum bcscheren".9\%

\section{Ermabnung und Appell}

Den ultimativen Strafen wic den Schlägen oder dem Freiheitsentzug gingen im Normalfall Ermahnungen und Appelle an Ehre, Einsicht und Alter voraus, sollte ein Kind einmal aufbegehren, ungehorsam sein und gegen scine Verhaltensnormen verstossen. Ein beliebter Appell von Vätern an (bereits etwas älterc) Jungen war:

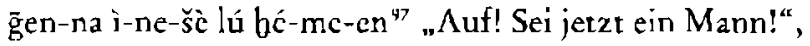

in den Worten Šamši-Addus an seinen Sohn Jasmaḩ-Addu lū awilāt „sei ein Mann!“" Derlei Aufforderungen sollten an den Jungen appellieren, endlich mit der Ernsthaftigkeit eines Erwachsenen dic an ihn gestellten Erwartungen zu erfüllen.

Vicle IDinge im Leben eines Kindes und jungen Erwachsenen wurden von seinen Eltern nur sehr ungerne gesehen. Dabei ging es nicht nur darum, cin Kind auf dem rechten Weg zu halten, damit es ans Zicl gelange. Nicht zuletzt konnte ein ungezogenes Kind auch für den schlechten Ruf seiner Eltern sorgen, wcshalb

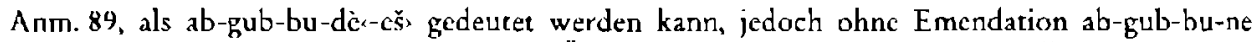
gelesen werden müßte. Dic sich crgebende Übersetzung „(Meine Schwestern) stellen (cin wic eine Tür festgegrundetes Frauengemach) auf" blicbe allerdings inhaltlich unklar.

4. Unklar ist mir, ob in den obigen Aussagen, die die antiken Meister einem der debattierenden Kontrahenten in den Mund legten, nicht cine feine Ironie lag. Die Äußerungen beziehen sich nämlich möglicherweise auf Wertvorstcllungen nicht schriftgebildeter Kreise.

"Vgl. hier die Bemerkungen von H. I. Marrou (wie Anm. 20), S. 7 („Unterricht ... als cincm Mittel des Emporkommens").

4. Examenstext D, Z. 11 u u$_{4}$-tur-ra-zu-ta nam-ma-si / ina șe-bुe-ri-ka ta-nam-ziq „Scir Deiner Kindheit hast Du Kummcr".

"Examenstext D, Z. 5 nam-dub-sar-ra bar-dag ù-bí-ak šu-nīg-ḡál-la a-ra-ab-tuku / ana (ț/up-šar$r u-t u_{4} \imath u-p \ddot{u}^{\prime}-m a$ maš-ra-a li-sar-ši-ka (vgl. PSD B, S. 118); ähnlich Examenstext D, Z. 10, vgl. Å. Sjöberg, JCS 24 (1972), S. $126 \mathrm{ff}$. mir Duplikat CT 5866.

" Der Vater und sein mißratener Sobn, 'Z. 28.

yR ARM 1 69, Z. 13'. Dic Äußcrung „sei ein Mann“ ist ausschließlich auf dessen mentales Erwachsensein bezogen (nıan würde andernfalls $l \bar{u}$ zikarät erwarcen). Vgl. hicrzu auch dic Überlegungen von A. Théoridès, L'enfant dans les institutions pharaoniques. In: L'cnfant dans les civilisarions orientales - Het Kind in de oosterse Beschavingen, Leuven 1980, S. 92 mit Anm. 14, sowie S. 99, Anm, 48 ( $n . .$. la qualité $d$ ', celle qui définit un être humain dans sa perfection administrative (et partant sociale et morale) ${ }^{u}$ ). 
man verständlicherweise doppelt besorgt war und die Kinder immer wieder ermahnte: ${ }^{99}$

„Steh nicht auf dern Marktplatz herum! !co

Treib Dich nicht auf der Straße herum! 101

Wenn Du durch die Gassen gehst, schau' nicht immer umher!

Sei demütig! Mögest Du Deinem Aufscher gegenüber furchtsam geworden sein! ${ }^{102}$

Wenn Du ihm stets Furchtsamkcit entgegen bringst, dann wird er Dir zugeneigt (geworden) sein!

Hab Ehrgeiz! Deinen Genossen erreiche!?

Geratc ihm gegenüber nicht in Rückstand! ${ }^{103}$

Deine Kollegen sollen Dein Anschen nicht beschmutzen!“ “ï4

Derlei Ermahnungen eines Vaters gegenüber seinem Sohn hatten wohl die meisten Söhne über sich ergehen lassen müssen, waren doch die genannten ,Themen' keineswegs auf den Bereich der Schule beschränkt. Innerhalb der Schule galten natürlich nochmals besondere Normen, dic jedoch of insofern über die Schule hinauswirkten, als ihr traditionell sowohl die Struktur einer Familie, ${ }^{105}$ dann aber auch dic eines Betriebes zugrunde lag. ${ }^{106}$ Schon die kleinsten, sicherlich auch in Mesopotamien schr lebendigen Schüler, hatten sich von Beginn an in dieses System einzufügen. Hierbei galt es nicht nur, Eifer, Demut,

" Der Vater und scin mißratener Sohn, Z. 29-36 tilla nam-ba-c-gub-bu-dè-en / sila-a nam-muniğin-dè-cn / e-sír-ra dib-bé-da-zu-dè igi nam-bar-bar-re-en / hé-sun;-nc-en ugula-a-zu ní bé-cmdè-te / ní-te-ní-te-a-zu-dè ugula-a-zu ki a-ra-an-äğ / ì-ma bé-tuku lú-tab-ba-zu sá dü-ga-n[a] / a-

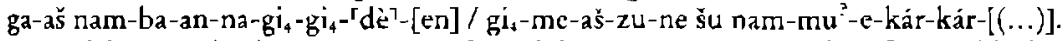

${ }_{10}$ Auf dem Marktplatz zu stehen, galt auch bei (jungen) Frauen als äußerst schlcchtes Benehmen: $x$

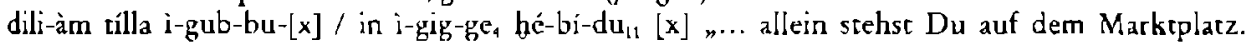
Furchrerliche Schimpfworte hast Du ausgesprochen" (Streit zweier Frauen (A), NBC 7805, Vs. 16-17, unveröff. MS von A. Cavigneaux).

101 Das Herumtreiben auf Straßen und Gassen war offenbar einer der meist kritisierten Fehltritte, auch bei den Frauen: e-sír-ra ì-ba-e-gub in al-[dúb-d]úb-bu „Kaum bíst Du auf die Straße getreten, schon schimpfst Du herum" (Streit zweier Frauen (B), 7. 70); sila-a gub-gub e-sír-ra nig̈in-niğin / $m i-t a-z i-z a-a t$ re-bi-a-tim sà-bi-ra-at su-qa-a-tim, überall in den Gassen stchend, sich auf den Straßen herumtreibend" (Streil 'rveier Frauen (B), Z. 111).

${ }^{102}$ Demut gilt als ciner der Fckpfeiler mesopotamischer Erziehung. So crzählt ein Aufseher einem Schüler aus sciner früheren Schulzeit: i-sun ${ }_{5}-n c-n a$ mu-da-ši-b̧úl silim-ğá i-ni-in-d $u_{11}$ „Weil ich demütig war, freute er (der Meister) sich über mich (und) lobte mich" (Schreiber und Aufseber, Z. 8 (CBS 15160, MS M. Civil).

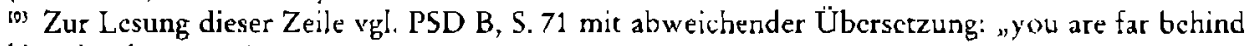
him (the classmate)".

10" Für šu--kár-kár = tuppulh „to dirry one's reputation", „to soil someone“ vgl. M. Civil, JAOS 103 (1983), S. 46, Anm. 8 (mit älterer Literatur).

oos Titel der Funktionsträger wie ad-da-é-dub-ba-a ${ }_{n}$ Vater des Tafelhauses" und šeš-gal ${ }_{n}$ groß̉er Bruder ${ }^{\alpha}$ reflekticren den familären Ursprung der „Schule“, vgl. hierzu H. Waetroldo, Das Schreiberwesen in Mcsopotamien (unveröff. Habil.-Schrift, Heidelberg 1974), S. 12 mit Anm. 40.

${ }^{106}$ Hierzu gchört die Fxistenz ennes ugula "Aufsehers“ in der Schule. 
Gehorsam, ${ }^{157}$ Aufrichtigkeit und Anstand als allgemeine Grundwerte zu beachten. Für die spezifische Ausbildung zum Schreiber hieß dies:

„Vernachlässige nicht die Schreihkunst, sei nicht müßig!"

Ein grundlegendes Anlicgen war es den Erwachsenen, die Kinder dazu anzuhalten, nicht zu trödeln, den Tag nicht ungenutzt vergehen zu lassen:

„Den Tag laß nicht vergehen, die Nacht låß keine Kühle bringen. Geh ihm zur Seite!“c199 All' diese Ermahnungen und Appelle verfolgten nicht nur den Zweck, ein Kind zu einem respektierten Mitglied der Gesellschaft zu machen, es sollte auch und insbesondere vor seinem Gott bestehen können:

„Finde Wohlgefallen vor Deinem Gott!"1" ...

Finde Wohlgefallen vor Nanna, Dcinem Gort, Ningals Blick, der Wohlgefällige, soll (daraus) resultieren"."1"

\section{Scblagen}

„Das Ohr eines Jungen sitzt doch auf seinem Rücken; er hört, wenn man ihn schlägt" ${ }^{112}$ So lautet cinc der Maximen altägyptischer Erzichungslchren, die sich inhaltlich kaum von dem alttestamentlichen „Wer seine Rute zurückhält, der

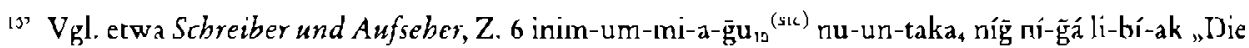
mir zuteil gewordenen Worte des Meisters vernachlassigte ich nicht, nichts tat ich von mir selbst aus".

:د Examenstext $D, Z .6$ nam-dub-sar-ra na-ab-il-cn á-zu na-an-šub-bć-en [ana] tup-šar-[r]u-tu, la $e-g a-a-t a$ ab-ka la ta-nam-di. Zu dicsem, vor allem lexikalisch problematischen nachaltbabylonischen Text, der thematisch aber auf Altbabylonisches zurückgreift, vgl. Å. Sjöberg, JCS 24 (1972), S. 126-131.

${ }^{1 c^{4}} u_{4}$ na-ab-zal-e-en $\bar{g} i_{f}$ na-ab-šed,-e-en á-ni-šc̀ (nur SRT 28 Vs. 13; 3 N-T 917, 388 (SLFN 47) Vs. 2 sowie 3 weitere unveröffentlichte Textzeugen schreiben á-bi-še) gen-na (Schrèber und Aufseber, Z. 18).

11. Der Vater und sein mißratener Sobn, Z. 176-177 igi-diğir-za-ka sa

111 Ebd. Z. 181-182 igi- ${ }^{d}$ nanna-diḡir-za-ka sa $a_{4}^{-i} /$ igi-bar-ra- ${ }^{d}$ nin-gal-la sa $a_{4}-$ ga hé- ${ }^{-}{ }^{\top}($ ?) (Text UU. Rs. 33; nach Kollation von M. Civil ist nach hé- kcin Zcichen mehr identifizierbar. Text G schreibt bié|-me-cn ( „Ningals Blick) soll (cin wohlgcfälliger) scin“).

:12 Aus dem Papyrus Anastasi III, ciner Schulhandschrift des Neuen Reiches (vgl. zu diesem Text H. Brunner (wic Anm. 16), S. 171 Qu. XXXVI). H. Brunner (wie Anm. 16), S. 56 beront: „Nach den Schultexcen des Neuen Reiches spielen dic Prügel die entscheidende Rolle, und daß das nicht erst eine späte Entartung ist, geht unter anderem aus der ägyptischen Schrift hervor ...". Auch in der Vater-Kind Bezichung spiclen Sehlägc mic dem Stock eine zentrale Rolle, vgl. E. Feucht, Zur Sozialgeschichec der Kindheir, S. 241 mit Anm. 105. Ähnliches wird aus dem antiken Griechenland überliefert: „so suchen sic ihn (d. Knaben) wie cin Holz, das sich geworfen und verbogen hat, wieder gerade zu machen durch Drohungen und Schläge" (Platon: Protagoras 325d, vgl. hierzu und zu weiteren Parallelen M. Deißmann-Merten, Sozialgeschichte der Kindheit, S. 301). 
haßt seinen Sohn; doch wer ihn liebt, der sucht ihn mit Züchtigung heim" "11. unterscheidet. Hiervon scheint sich das in Mesopotamien geläufige, allerdings einem ganz bestimmten sozialen Milieu zugeordnete Sprichwort ${ }^{14}$ "Ein Armer schlug sein Kind niemals mit der Faust. ${ }^{15}$ Als cinen ,Schatz' behandelte er es" ${ }^{116}$ deutlich abzuheben.

Schlagen als disziplinarisches Mittel kennt man narürlich auch im Alten Mesopotamien. Nach der Überlieferung des 3. und beginnenden 2. Jahrtausends scheint man Schläge zwar als übliches, aber nicht einzig erfolgversprechendes Erziehungsmittel betrachtet zu haben, das im Idealfall nicht zur Anwendung kommen sollte ${ }^{117}$ und in bestimmten Kontexten als disharmonisch empfunden wurde. So betont der neusumerische Stadtfürst Gudea von Lagaš, daß im Zusammenhang seiner Bautätigkeit ${ }^{118}$ am Tempel Eninnu des Stadtgottes Ningirsu keine Mutter ihr Kind schlug. ${ }^{119}$ Schläge galten nicht als ultima ratio. Ein verzweifelter Vater ließ schon einmal davon ab, seincn Sohn zu schlagen, weil er die Wirkungslosigkeit solchen Tuns erkannte, ja darüber selbst betrübt wurde:

${ }_{\text {w }}$ (Dich) zu schlagen (und nocheinmal) zu schlagen, da wurde ich nur betrübt. (Dcshalb) habe ich Dir freien Lauf gelassen." 120

\footnotetext{
113 Proyerbia 13:24.

114 CBS 13944 Rs. iii 2-3 (SP 17, cf. B. Alster, RA 72 (1978), S. 102) úku-re dumu-na tibir diš-àm šu nu-um-ši-in- $d_{u_{11}}-{ }^{\top} \mathbf{x}^{\top} \mathrm{gj}_{16}-s a$ da-ré-és mu-un-[x]-ni-ak-[àm]. Die parallel überlieferte, jedoch teilweise zu ergänzende Version SP 223 úku-re dumu-ni tibir diš-àm [šu mu-un-ši-in-du $\left.{ }_{11}\right]^{\prime} / \mathrm{gi}_{16}$-sa daré-ěš nu-mu-[ni-in-ak-àm] (vgl. E. Gordon, Proverbs, S. 191 f; P. Atringer, ÉLS, S. 701, Ex. 423) ist nur dann sinngemäß der erstgenannten, wenn man sie als Frage interpretierc (Hinweis $C$. Wilcke): „Schlug ein Armer sein Kind jemals mit der Faust? Behandelte er es nicht als Schatz?“. Zu Problematik der Deutung dieses Sprichwortes s. oben S. 181 mit Anm. 28.

115 tibir (TAGxŠU) verstehe ich hier als upnu "(geballe) Hand", „Faust", wenngleich für tibir auch die akkadischen Äquivalente ritu "Hand" und qäıu "Hand“ (vgl, Aa V/1, Z. 254-255, s. MSL 14, S. 414) bezeugt sind.

116 Ein Kind war gerade in den unteren sozialen Schichten als Arbeitskraft unverzichtbar. Man vermied also das 5 chlagen, um seine Arbeirskraft niche durch eine eventuelle Verletzung zu mindern oder sie durch sein Weglaufen gar zu verlieren. Merkwirdig blesbe dennoch die Einschränkung der Aussage des Sprichwortes auf die Armen. Sollte hier etwa implizit vermittelt werden, ein Reicher könne sein Kind bedenkenlos schlagen?

117 Der Ratschlag Šuruppags an seinen Sohn Ziusudra „Du sollst den Sohn eines Bauern nicht schlagen, er hat (schlieißlich) Deine Bewässerungsgräben angelegt ${ }^{*}$ (s. Unterweisungen des Šuruppag, Z. 158; dazu B. Alster, Mesopotamia 2, S. 43; C. Wilcke, ZA 68 (1978), S. 208; W. H. Ph. Römer, TUAT IIL/1, S. 59 zeigt, daß ein Erwachsener sich sehr genau der Konsequenzen seines Handelns bewußt zu sein hatte.

117 Hierfür war nicht nur eine große Anzahl von Menschen vonnöten. Auch kulcisch-rituelle Voraussetzungen muliten für einen solchen Bau gegeben sein.

119 Gud. Stat. B iv 12 ama dumu-ni níg nu-ma-ni-ra „Die Mutter schlug ihr Kind nicht" (vgl. H. Stciblc, FAOS 9,1, S. 161 mit Anm. 27 (FAOS 9,2, S. 14)).

${ }^{220}$ sig-ge-dè sig-ge-dè zi ba-ir šu ba-e-ri-bar (Der Vater und sein mißratener Sohn, Z. 62, vgl. Å. Sjöberg, JCS 25 (1973), S. 111 ff. In den noch nicht vollstandig wiederherstellbaren Zcilen 141142 dieses Textes macht sich der Varer offenbar letzlich doch Vorwürfe über sein inkonsequentes Verhalten: mu [...] nu-un-sìg-sìg-ga-ke+teš / mu KA-ra nu-un-tag-tag-ga-ke,-č̌ ... ${ }_{n}$ Weil ich ${ }^{2}[\ldots]$
} 
Kurz zuvor noch hatte der Sohn seinem Vater vorgeworfen:

„Dein weises Handeln und Dein Prügeln, Deine Eigenschaften, in denen es Dir keiner glcichtur! Bin ich Dir denn geschaffen als einer, der dic Vorschriften nicht befolgt, bin ich in Deiner Hand kein Mensch?" "121

Wenig Sentimentalitär, zumal cs sich ja nicht um die eigenen Kinder handelte, zeigten die Schuloberen, die die Schreiberschüler für cin jeweils eindeutig bestimmes Fchlvcrhalten schlugen. Interessanterweise wird gerade in diesen Kontexten das Verbum túd verwender, geschricben mit den Zeichen für uzu "Fleisch" und PA/g̃idru "Stock". ${ }^{\text {"2z }}$ Zeitlos klingt der folgende Abschnitt aus den Vorschriften des Edubba'a: ${ }^{123}$

„Wenn ein kleiner Schreiberschüler

sein Exzerpt ${ }^{124}$ und seine Wortliste ${ }^{125}$ nicht auswendig gelernt hat, wird ihn der, große Bruder und der Vater des Tafelhauses schlagen“. ${ }^{26}$

Ebcnso wic in $\ddot{A}$ gypten war das Trödeln, Nichtstun, Faulsein in der Schule, aber auch sonsı im Leben, ganz besonders verpönt. ${ }^{127}$ Müßiggang, das lernte jedes Kind, war ein Tabu. ${ }^{12 R}$ Kam es dennoch dazu, waren die Konsequenzen sofort klar:

nichr immer wieder geschlagen habe, weil ich' ... nicht immer wieder geprügelt habe“. Der Text fährr in Z. 144 fort: „Was isc jetzt \%u tun?" (a-na-àm i-ri-AK).

${ }^{\prime \prime \prime}$ Der Vater und sein mißratener Sohn, Z. 55-56 úmun ak uúd-zu (Texte $\mathrm{J}_{1}, \mathrm{~L}, \mathrm{Ur}_{1} \mathrm{Ur}_{\mathrm{r}_{1}}$; Var.: túd-da (K); túd-dè (J)) níg̃ nu-mu-e-da-sè-ke-da-zu / á-áğğgá nu-dab ${ }_{4}$-ba-gim a-ra-dím-en šu-za lú nu-mecn.

${ }_{122} \mathrm{Zu}$ den im Alten Ägypren verwendeten Zeichen für „schlagen“ vgl. H. Brunner (wie Anm. 16), S. 56.

123 PBS 1/2 98 (= PBS 12/1 30), Rs. 5'-7' tukum-bi dumu-é-dub-ba-a-cur-re / SAR-šub-bạ-ni ù mugub-ba-ni ka-ka-na li-bí-in-sè / šeš-gal-e ad-da-é-dub-ba-a-ka-ni an-túd-dè.

124 Der Terminus SAR-šub-ba ist im Zusammenhang der altsumerischen Verwaltungsurkunden von V. Christian AfO 19 (1959/60), S. 131 (mit àlterer Literatur) als „Zusammenfassung von Schlußsummen aus Einzeltexcen", d. h. "A us'rug" gedeutet worden. Inwieweit diese, in die obige Übersetzung übcrnommene Interpretation auch für unseren Kontext zutreffen konnte, bleibt vorerst unsicher. Vgl. dic völlig abweichende Ansicht von B. Landsberger MSL 9, S. 141, Anm. 1. Nach M. Civil, ABD Il, S. 303 sub C., bezeichnet SAR-šub-ba eine Übungstafel, deren Vorderseite vom Lehrer und deren Rürkscite vom Schüler (jedoch nicht immer mit einem zur Vs. Identischen Stoff) beschrieben wurde.

12s Mir dieser Interpretation von mu-gub-ba folge ich mit allem Vorbehalt M. Civil, ABD II, S. 303 sub C. Beachee jedoch, daß M. Civil, FS Biror, S. 75 ad 19 mu-gub-ba als „Hausaufgabe“ deurer.

126 M. Civil, ABD II, S. 303 sub C. nimmt, nach seiner Übersetzung zu schließen, für Rs. 7’ offenbar eine andere Worttrennung an: šeš-gal-e ad-da-é-dub-ba-a KA-ni an-túd-dè nthe instructor and the mastcr will strike his face“. Vgl, 7u dieser Stelle bereits A. Falkenstein, WO 1 (1948), S. 177.

12) H. Brunner (wie Anm. 16), S. 56 und 173 f. Qu. XXXVIII d. (Papyrus Anastasi V) „Verbringe kcinen faulen Tag, oder wehe deinen Gliedern".

${ }^{228}$ Schreiber und Aufseber, Z. 14 gú-zi-zi ba-la-á-áğgágá-kam u,-zal-le níğ-gig-ga „Frühes Aufstehen ist Bestandteil der Vorschriften. Müßiggang ist ein Tabu“ (SRT 28, Vs. 4; zur Interpretation von gú- 
"Den Tag darf ich nicht vertrödeln, mein Meistcr wird mich sonst schlagen“.'129 Schläge im spezifischen Zusammenhang der schulischen Ausbildung zum Schreiber gab es aus mannigfachen Anlässen und von den verschiedensten Personen. Sowohl der äußeren Ordnung im schulischen Alltag ${ }^{130}$ wie insbesondere dem strikten Gehorsam gegenüber den Schuloberen galt alle Aufmerksamkeit: ${ }^{131}$

„Dcr (für das) Schweigen(?) zuständige Mann (sprach): Warum hast Du ohne meine Erlaubnis den Mund aufgemacht? - Da schlug er mich.

Der ,Mann mit den Vogelfedern' ${ }^{132}$ (sprach): Warum bist Du nicht früh (genug) aufgestanden? ${ }^{133}$ - Da schlug er mich.

Der Mann für die Vorzeichnungen ${ }^{134}$ (sprach): Warum hast Du Dich ohne meine E.rlaubnis crhobcn? - Da schlug er mich.

zi-zi vgl. J. van Dijk, La Sagesse, S. 25). Diese Aussage ist Teil der Vorschriften, die der Meistcr (ummi-a) cinst cincm Schüler beizubringen suchte, der sie, mittlenweile selbst zum Aufscher (ugula) emporgesticgen, nun einem jungen Schüler eriählt.

${ }_{129}$ Der Sohn des Tafelbauses, Z. 17 u na-ab-zal-e-en um-mi-a-g̃u $u_{1 c}$ mu-un-túd-dè(-en). Die geschilderte Situation trifft aber sicherlich auch für Kinder in cincr handwcrklichen Ausbildung zu, deren Meister ja ebenfalls um-mi-a genannt wurde.

190 Vgl. Der Sahn des Tafelhauses, Z. 29 lú-tag-tag-gc-da-kc sila-a igi i-ní-in-bar túg-GABA-zu/-za nu-ub-(bu)-ús e-še in-túd-dè-en „(Sprach) der für das Schlagen zuständige Mann: ,In den Gassen hast Du horumgeschaut. Du hast das Gewand nicht an Deiner Brust anliegen lassen(?) - Da schlug er mich" (Texte: SLTNi 118 ii 4; CBS 6094 i 20' (Var.: nu-ub-bu-re"'); CBS 19826 , side B', Z. 8', sowie MS M. Civil). M. Civil, ABD II, S, 304 sub G übersetzt die Zeile: "the man in charge of the felted cloches $\left[\mathrm{LU}_{2}\right.$ TAG-TAG, to be spread down at each pupil's sitting place] looked into the aisles and said: "your felt is not picked clean!" $\Lambda$ uf einen ähnlichen Zusammenhang spiclt vielleicht UET VI 168, Rs. 5 (Vorschriften des Edubba'a) an: lú-tag-tag-ge-da-kc si sla ...] saḩar-ŠES ab-DU-[...].

${ }^{13}$ Der Sabn des Tafelhauses, Z. 35-41 lú-si-TUR-kc $c_{4}$ a-na-šc-àn ğá-da nu-me-a ka i-ba e-še in-túddè-cn / (36) lú-pa-mušen-na-ke 4 a-na-še-àm gú-z.i nu-mu-e-zi c-šc in-túd-dè-cn / (37) lú-ḡiš-hur-ra-

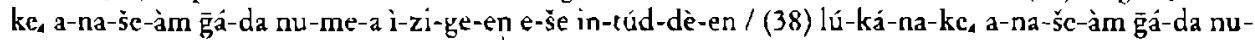

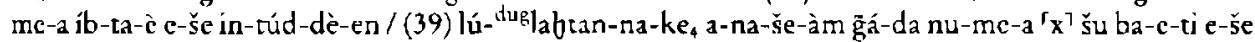
in-túd-dè-en / (40) lú-eme-gi,-ra-ke, eme-uri bí-in-du $u_{11}$ e-še in-túd-dè-cn / (41) um-mi-a-ğgu nu-sa $a_{6}-5 a_{6}$ e-še in-túd-dè-en (vgl. ru diesen Zeilen M. Civil, ABD II, S. 304). Zusätzlich zu den publizierten Quellen (vgl. ÉL.S, S. 34) sind hicr unveröffentlichte mit herangezogen, die mir M. Civi] in dankenswerter Weise überlassen hat.

132 lú-pa-mušen-na wird häufig in den Edubba'a-Textcn crwähnt, ohne daß eine genaue Bestimmung seiner Funktion erfolgen könnte. Der wörtlichen Bedeutung nach (,Mann der Vogelfedern “) könnte er vielleicht ein Lufrfächler gewesen sein. Völlig unklar bleibe bei dieser Deurung, in welchem Zusammenhang diese Tàtigkeit mit gú--øi „früh aufstehen" (wörtl.: „den Nacken crheben“, des Schülers steht.

${ }_{133}$ Nach Schreiber und Aufseher, Z.14 ist frühes Aufstehen Bestandtcil der Vorschriften des Edubba'a, vgl. oben Anm. 128.

${ }_{14}$ G̈jó-bur-ra verstehe ich hier nicht ais „(Vcrhalcens)regcin“ (so W. H. Ph. Römer, TUAT III/l, S. 72), da im Kontext der Schule hierfür à-áğ-ğá verwendet wird. Vielmehr geht es hier um die Vorzeichnung ( zeichnet, vgl. Der Sohn des Tafelbauses, Z. 32, dub-g̃u ${ }_{1}$ šu ba-ti ğiš-ḩur ğiri-g̃á al-thur „Meine (noch unbeschriebene) Tafel erhielt ich, die Vorzeichnung wurde zu meinen Füssen gezcichnet" (s. auch M. Civil, ABD II, S. 304). 
Der Türhüter (sprach): Warum bist Du ohne mcine Erlaubnis hinausgegangen? - Da schlug er mich.

Der Mann des Wasserkruges (sprach): Warum hast Du ohne mcine Erlaubnis [Wasser?]

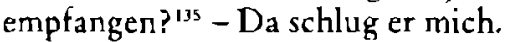

Der Sumerischlehrer (sprach): Du sprachst Akkadisch. ${ }^{136}$ - Da schlug er mich.

Mein Meister (sprach): Deine Hand(schrift) ist überhaupt nicht gut. - Da schlug er mich".

Manchmal genügte schon, wenn der Vater des Tafclhauses (ad-da é-dub-ba-a) entdeckte, daß ein Schriftstück beschädigt sei: „(Er sagte): ,Weil ctwas davon (von der Tafel) abgebrochen ist', (und) schlug mich". ${ }^{137}$ Kann es hier verwundern, daß ein derart geplagter Schüler dic Schule zu hassen begann? ${ }^{138}$

In ganz besonders eklatanten Fällen drohte man über die, üblichen' Schläge hinaus mit 60 (Kculen-) Schlägen mit dem dubdimmu, ${ }^{139}$ einem bisher nicht endgültig identifizierten Objekt. ${ }^{125}$

\section{Freibeitsstrafen}

Halfen Ermahnungen, Drohungen oder ,einfache‘ Schläge bci der schulischen Ausbildung nichts, so wurde im äußersten Falle die Bewegungsfreiheit des Schülers durch Hausarrest, ja sogar durch Fußschellen eingeschränkt. Diese von der Antike ${ }^{141}$ bis in dic Moderne gebräuchliche Zwangsmaßnahme ist im Mesopotamien der altbabylonischen Zcit und sicherlich auch schon früher vor dem Hintergrund der Bloßstellung eines Schulkollegen angedroht und wohl

\footnotetext{
135 Vgl. zu dieser Aussage PBS $1 / 298$ (= PBS 12/1 30), Ks. 9-10: [lú]-a-a-ke, dug daba-ba-ab lú-[M

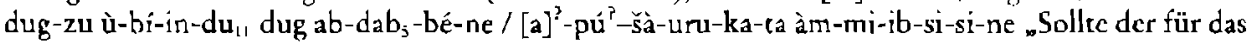
Wasser zuständige [Mann] (immer wieder) sagen: Den Krug nimm! Idiot, Deinen Krug (nimm endlich!), dann nehmen sie ihn (und) füllen [Wasser] aus dcm Brunnen" ir der Stadtmictc cin".

13. Ich folge hier UM 29-13-591, zitiert von A. Sjöberg, ZA 83 (1993), S, 1. Die Texte A, C, E. K und Am sind ohne Kollation nicht verwertbar (KU'. GAR 'dcutet auf uri'). Die Aussage der Zeile bezieht sich nur auf eine bestimmec Phase des Unterrichts, in der nicht akkadisch gesprochen werden sollte (woraus sich aber entgegen J.-M. Durand, N.A.B.U. 1994, Nr. 6 nicht zwangsweise ablciten läßt, daß3 das Sumerische als tote Sprache anzusehen wärc). Daneben gab es spezifische Untcrrichtseinheiren, in denen die Zweisprachigkeit, das Übersetzen vom Sumerischen ins Akkadische und vice versa, gezielt geübt wurde. Vgl. hierzu demnächst M. Civil, Bilingual Teaching (in: Tikip santakki mala bašmu ... [wie Anm. 28]).

137 Der Sahn des Tafelbauses, Z. 26 mu im-ta-kud-rá-aš c-šc in-rúd-dè-en.

138 Ebd. Z. 42 nam-dub-sar-ra gú bí-dù „Die Schreibkunst hasste ich (deshalb) ${ }^{\alpha}$.

$139 \mathrm{Zu}^{\overline{1} 1 \mathrm{~s}} \mathrm{dub}$-dim = dubdimmis, vgl. AHw, S. 174; CAD D, S. 168; MSL IX, S. 168 ad MSL V, S. 152

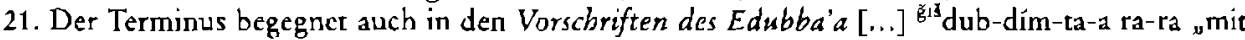
dem dubdimmu schlagen(d)" (UETT VI/3 240, unveröff. MS M. Civil).

${ }_{140} \mathrm{Vgl}$. zu diesen Zeilen unten, Abschnitt 7., "Freiheitsstrafen“.

$14 \mathrm{Vgl}$. H. Brunner (wie Anm. 16), S. 57; auch das islamische Ägypten kennt den Block, in den die Füßc eines zu bestrafenden Schuljungen eingeschlossen werden, vgl. E. Littmann, Arabische Märchen und Schwänke aus Ägypten (Mainz 1955), S. 42.
} 
auch angewandt worden. Hat man im Alten Ägypten die pädagogische Perspektive des Freiheitsentzuges, eine intensivere Konzentration auf die wesentichen Aufgaben und im Ergebnis eine bessere Leistung des Schülers im Auge, ${ }^{1+2}$ so wird diese Frage in den Edubba'a-Texten nicht diskutiert, weil der Maßnahme ein Verstoß gegen die Vorschriften vorausging, der auch nach Abbüßen der Strafe nicht als abgeschlossen betrachtet werden konnte: ${ }^{143}$

„Wenn ich Dir gegenüber nach meinem eigenen Willen handeln (könnte), wuirde ciner, der wie du handel, dafür, daß er seinen ,großen Bruder' lächerlich gemacht hat, ${ }^{144}$ nachdem er (erst einmal) mit dem dubdimmu 60 (Keulen-)Schläge verabreicht bekommen hat,

nachdem cr kupferne Fesseln an scine Füsse angelegt bekam, im Haus umhergehen und aus dem Edubba'a für zwei Monate nicht herauskommen“. ${ }^{145}$

Über die genannte Stelle hinaus erfahren wir in unseren Texten nichts, was darauf hindeutete, daß man die Freiheitsstrafe als erfolgversprechende erzicherische Maßnahme verstanden und deshalb auch wiederholt angewandt hätte.

Bei der Darstellung der Mittel und Methoden, den Arbeitseifer eines Kindes oder Schülers zu steigern, stand bisher, wesentlich aufgrund der Überlieferung, die Lebenssituation von Familien des bürgerlichen Milieus der altbabylonischen Zeit im Vordergrund. Von den Unterprivilegierten war hingegen nur in Ausschnitten die Rede. Die Methoden, mit denen man versuchte, Prinzessinnen und Prinzen auf ihre spezifischen Aufgaben vorzubereiten, bedürfen einer gesonderten Betrachtung, da allein der soziale und organisatorische Kontext, ${ }^{146}$ in dem

\footnotetext{
142 Ein altägyptischer Lehrer erzählt einmal seinem Schüler: „Wenn Du mich selbst ansiehst: $\Lambda \mathrm{ls}$ ich in Deinem Alter war, da verbrachte ich meine Zeit im Stock; er war es, der mich gebändigt hat. ... Er wich erst wieder von mir, als meine Hand geschickt war und ich den übertraf, der mir vorausgewesen, als ich an der Spitze aller meiner Kameraden stand und sie in den Schriften ubertroffen hatte $^{*}$ (H. Brunner (wie Anm. 16), S. 173, Qu. XXXVIIIc).

${ }^{143}$ Diesen Hinweis gibr Enkimansum und Girini isa, Z, 186: i-ne-šè nam-tag-zu ba-ra-du "Somit soll Deine Schuld (aber noch.) nicht gelös sein!“ Zwar erwahnt der Text selbst dies nicht ausdricklich, doch ist für die Freisprechung von derlei Schuld der in den Edubba'a-Texten so bezeichnete lúnam-tag(-ga) „der für Vergehen zuständige Mann“ vorgesehen.

${ }^{144}$ Das zusammengesetzte Verbum sag̃--DU, das mehrfach in der Edubba'a-Literatur gebraucht

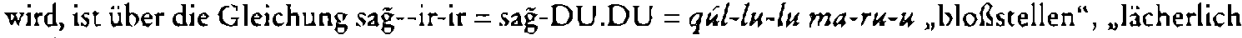
machen" (s. MSL IV, S. 27, 11 und MSL. XVII, S. 215, 73 sag̃--1)U = qúl-[lu-lu]) zu interpretieren. Vgl. auch sağ-túm-ma = magirtum "Beleidigung" (s. CAD M/I, S, $44 \mathrm{f}$. mit discussion section).

${ }_{145}$ Enkimansum und Grnni' isa, Z, 181-186; tukum-bi niğ-šà-ğá e-ri-ib-ak-en / lú za-e-gim ak šeš-

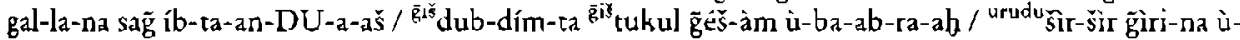
ub-sè-ke / é-a an-nig̃in-ma é-dub-ba-a-ta iti 2-àm nu-ub-ta-è (vgl. zum Text die Partiturumschrift von W. H. Ph. Römer, UF 20 (1988), S. 239 ff. und dessen Übersetzung ibid. S. 242 und TUAT III/1, S. 97). Für $Z$. 183 ist ein unvcröff. MS von M. Civil herangezogen.

146 Einen Einblick in die matcriclle Ausstattung, dic einer mit ihren königlichen Eltern reisenden Prinzessin bzw. einem Prinzen an einem, gastgebenden' Ort zustand, gibt der spätsargonische Text

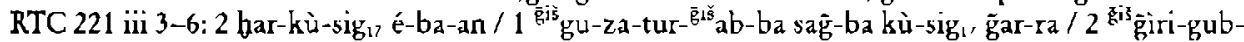
tur / dumu-lugal-me 2 paar goldene Ringe; 1 kleiner Thronsessel aus a-ab-ba-l Iartholz oben mit Gold plattiert; 2 kleine Fußschemel; (für) die Königskinder". Eine direkte Parallele zu diesem Text
} 
sich dic Fürsten- und Königskinder bcwegten, deutlich von jenem der bisher vorgestellten Bevölkcrungsschichten unterschieden war. Darüberhinaus bieten dic oben zugrunde gelegten Quellen zwar eine Vielzahl von Aspekten der Erziehung und Ausbildung, aber keinerlei konkrete Aussagen, aus denen man erwas über das Dasein von Prinzessinnen oder Prinzen erführe. Um also Auskünfre über unscre Fragestellung zu erhalten, müssen wir auf ein vollständig anderes Genre, das der Königshymnen, der Königsinschriften, der Briefe und der Weishcitstexte ${ }^{147}$ zurückgreifen.

Allcm Anschein nach durchliefen dic Kinder der Fürsten- und Königshöfc im Laufe ihrer Schulzeit ähnlichc Ausbildungsabschnitte wie ihre nicht-höfischen Kollegen. Zwar halten die Quellen, wenn überhaupt, meist nur das Endergebnis einer schulischen Ausbildung als solche fest und schwcigen darüber, wie Prinzcssinnen und Prinzen ihren schulischen Alltag erlebten, doch gibr uns König Šlgi von Ur in ciner der ihm gewidmeten Hymnen (Šulgi B, Z. 13-20) wenigstens einen knappen, aber aufschlußreichen Abriß über die Phase sciner Schulzeit: ${ }^{148}$

ist RTC 222 iii 11 - iv 3, wo dic glcichen Objekte jedoch in andercr Anzahl noticrt werden. Vgl.

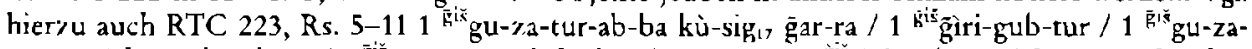
munus / dumu-lugal-me / 1 gुiš gu-za-tur-ab-ba kù-sig, klciner Thronsessel aus a-ab-ba-Harcholz mit Gold plattiert; 1 kleiner Fußschemel; 1 schmaler Thronsessel; (fur) die Königskinder. 1 klciner Thronsessel aus a-ab-ba-Hartholz mit Gold plartiert; 1 klciner FuRschernel; (für) die Prinzessin. "RTC 221 iii 7 ff. und RTC 222 iv $4 \mathrm{ff}$. zählen noch cine großc Anzahl von Gebrauchs- und Luxusgürern auf, die für die konigliche Familic (und ihre Entourage) zur Verfugung gestcllt werden, darunter Becten in verschiedener Ausführung (RTC 221 iv 2ff.), Schuhe, Sandalen (RTC 221 vi 21-22; RTC 222 v 19-20) Kopfschmuck (RTC 221 vii 22; RTC 222 iv 12) sowie Aromatika ( $\mathrm{R}^{\prime} \mathrm{I}^{\circ} \mathrm{C} 221$ vii 17') und Körperpflegemitrcl (RTC 221 vii 19’: 120 siğ-nağa „120 Blöcke Seife“). In diesem Kontext zu nennen ist u. a. auch M. Lambert, TÉl Nr. 56A, (vgl. hierzu C. Wilcke, Geschlechtsreife ..., S. 292, Anm. 115), CTMMA I, Nr. 17 i 4 - ii 56 (Lieferungen von Vieh an diverse Prinzessinnen der Ur-III-Zeit und köngliche Ammen, vgl. H. Neumann, JNES 53 (1994), S. 62) sowic dic umfangreiche und hochwertige nidittum "Mirgif" der Š̀mārum aus Mari, worunter Gold- und Silberschmuck, bronzene Gefässe, Kleider und Stoffc, Mohiliar aus Holz sowie Personal cinschließlich eines Schreibers zählte, vgl. hicrzu B. Lafont, CRRA XXXIII, S. $118 \mathrm{f}$.

W Zum Begriff der Weishcitslitcracur im Alten Mesopotamien s. D. O. Edzard, RlA 7, S. 45 \$ 3.7.3.; W. Röllig, op. cit., S. 59, $\$ 4.7$.

${ }_{14}$ Sulgi B, Z. 13-20 (Textsiglen nach G. R. Castellino, St.Sem. 42, S. 27-29. Zu Text A (SI'VC 52+) vgl. P. Gerardi, OPBF 8, S. 89; zu Tcxr F (UM 29-16-411)+G (UM 29-16-408+29-16-414a)+vgl. P. Gerardi, OPBF 8, S. 218; Kollacionen zu Text B gehen auf C. Wilcke zurück).

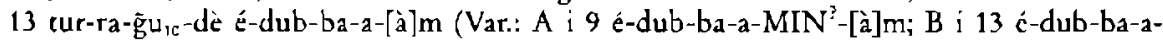
$\because \mathrm{MIN}-\mathrm{àm})$

14 dub-ki-en-gi-ki-uri-ka nam-dub-sar-ra mi-ni-zu (Var.: D, Z. 1 ki-ur[i]-ke,; E i 2 ki-uri-e$\mathrm{ka})$

15 nam-dumu-gi, gaá-gin,-nam im nu-mu-sar (Var.: B i 15 im nu-mu-un-esar)

16 nam-dub-sar-ra ki-nam-kù-zu-ba ir? im-mi-DU-DU (Var:B i 16 *i? ? $^{2} \mathrm{ir}^{3} \mathrm{im}$-mi-ri-ri; D, Z. 3 [... k]ì nam-kù-zu-gim)

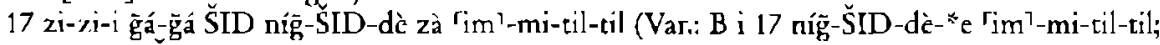
D, Z. 4 níg-ŠID.GU.KA [...]) 
"Als ich klein war, habe ich im Edubba a ${ }^{149}$

auf den Tafeln von Sumer und Akkad die Schreibkunst erlernt.

Keiner der Eínheimischen schrieb Tafeln so (gut) wic ich.

Am Ort der Weisheit für dic Schreibkunst habe ich .... ${ }^{\text {isj }}$

Subtrahicren, Addicren, Zählen bci ${ }^{2}$ der Abrechnung habe ich zu Ende gebracht.

Die schöne Nanibgal und Nisaba

haben mir Verstand und Einsicht großzügig verliehen.

(Jetzt) bin ich ein Schreiber, der (der Schreibkunst) geöffnet ist, ${ }^{151}$ der an nichts vorübergeht".

Nach Šulgis Darstellung besuchte er also schon zu früher Kindheit ${ }^{192}$ cine, möglicherweise sogar zwei Schulen, ${ }^{153}$ lernte dort nicht nur Sumerisch und Akkadisch, ${ }^{154}$ sowie das Rechnen, ${ }^{155}$ sondern rühmt sich auch als Bester aus dem Wettbewerb mit seinen Konkurrenten hervorgegangen zu sein. Hieraus wird man schließen dürfen, daß Šulgi seine Kenntnisse nicht aus cinem individucllen Einzelunterricht bezog, sondern den Unterricht der Meister und ,großen Brüder‘ am Edubba'a des königlichen Palastes zusammen mit den Söhnen arrivierter Palastschreiber genoß.

Schenkt man weiterhin den Aussagen vergleichbarer Hymnen Glauben, so sollten auch Könige der altbabylonischen Zeit wie etwa Lipitištar ${ }^{156}$ und sein

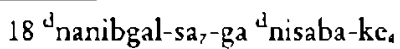

19 ğéštu ğizzal šu-dağal ma-ni-in-du $u_{11}$ (Var.: D, Z. 6 ma-ra-an-d $\left[u_{11}\right]$ )

20 dub-sar-ğál-taka $-a$ níg-c nu-dib-bé-mc-cn (Var.: D, 'L. 7 nu-dib'(LUU')-bé'-me-en)

${ }^{149}$ Nach den beiden unbeschädigt crhalecnen 'Textzeugen A und B (s. vorige Anmerkung), konnte (vorbchalclich cincr Kollation zu Tcxr A) mit ć-dub-ba-a-MIN-àm gemeint sein, daß Šulgi 2 Schulen (eine sumerische und cine akkadische oder zwei vcrschiedene Lokalitäten?) besuchte.

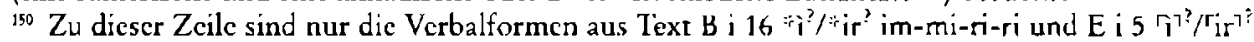
im-mi-DU-DU crhalten. Wie dic vermutlich parallelen Verben DU.I)U und ri-ri (steht DU.DU//ri-

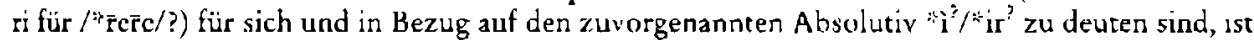
mir unklar. Vgl. zur bisherigen Diskussion dieser schwierigen 7eile M.-C. Ludwig, SANTAG 2, S. 184 mit Anm. 456.

${ }^{131} \mathrm{Vgl}$. zu dicscr Aussage im Zusammenhang Enmerkar und der Herr von Aratta, Z. 320-321

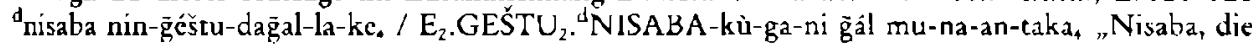
Herrin von weitem Verstand hat ihm (Enmerkar) ihr rcines Haus, Weisheit (der) Nisaba' geöffner". ${ }^{152}$ Bedauerlicherweise macht auch Šulgi keine genauen Angaben darüber, mit welchem Alter er die Schule besuchte. Es ist zu vermuten, daß er schon gleich nach der Entwöhnung, also in seinem 4. Lebensjahr mit dem Schulbesuch begann, wo zunächst das Auswendiglernen systematisch geübt wurdc. Auch im Alten lsracl gibt es vercinzelte Hinweise darauf (vgl. insbesondere Jesaja 28:9-10), daß glcich nach der Entwöhnung (zwischen 3 und 5 Jahren) mit dem Auswendiglemen in der Schule begonnen wurdc (s. A. Lemairc, ABD II (1992), S. 310).

(s) Vgl. hierzu oben, Anm. 149.

is Zum zweisprachigen Unterricht in altbabylonischer Zeit vgl. demnächst M. Civil, Bilingual Teaching, in: Tikip sancakki mala bašmu ... (wic Anm. 27).

155 Vgl. hierzu Anm. 184.

${ }^{156}$ Vgl. etwa Lipitištar B, Z. 19-24a (vgl. W. H. Ph. Römer, SKIZ, S. 24; H. Vanstiphout, JCS 30 (1978), S. 36 ff.; Partiturumschrift S. 40 ff.) (19) munus-zi dub-sar nin núg̈-nam zu / (20) si-zu (Var. AO 8863 (TCL 16 87) ii 17 [Text A] 'šs' -si'-zu') im-ma si ba-ni-in-sá/(2I) šà-dub-ba-ka gu-sum mi-ni-in-sa $-s a_{6} /(22)$ gi-dub-ba-kù-sigh -ka šu mu-ni-in-gùn / (23) gi-1-ninda éš-gána-za-gìn / (24) 
Vorgängcr Išmedagān ${ }^{157}$ einc Schulausbildung ähnlich derjenigen Šulgis hinter sich gebracht haben, wenngleich sie sich, soweit übcrliefert, offenbar nicht als Jahrgangsbeste' hervorhoben.

Nicht alle Könige konnten indes auf eine schulische Ausbildung zurückblicken. ${ }^{158}$ Schließlich gab es für derlei Angelegenheiten in der Regel einen ganzen Stab von kundigen Beratern. Manch ciner konnte nur eine Karriere beim Heer vorweisen, ${ }^{134}$ insbesondere die nicht wenigen Usurpatoren, ${ }^{160}$ jedoch fehlen aussagekräftige statistische Daten, um bcurteilen zu können, wann und unter welchen Bedingungen Schulbildung Bciwerk oder sogar Voraussetzung zum Erlangen des Königsthrones waren.

Erziehung zum Prinzen fand im Kindesalter natürlich nicht nur unter Leitung von Erziehern ${ }^{161}$ statt, sondern auch - ganz traditioncll - im Umfeld des Vaters, denn bei ihm war aus der Nähe mitzuerleben, wie man sich als Diplomat,

ras,'-lum lc-um igi-ğál šúm-mu (Var. Ni 1601 (ISET 1, S. 106), Vs. i 21 [Text F] le-um-c; Var.: SLTNi 69, Vs. 7 [Texr G] ğisas -lum le-mu-um) / (24a) dnisaba-ke, šu-dag̃al ma-ra-an-du ${ }_{11}$

„(Nisaba, die), rcchee' Frau, (die) Herrin, die alles wciß:

Deinc (Lipitištars) Finger führte sie auf der ' Tontafel,

in der Rechentabelle machte sie die Keilschriftzeichen schön,

machte die Hand mit einem Rohrgriffel aus Gold ,bunt'.

Den Meßstab aus Rohr von cinem nindan Länge und die blaue(?) Meßleine,

dic Meßschnur (von einem ašlu Länc) und die (wachsbeschichtcte?) Holztafcl, die Weisheit verleiht, hat Nisaba Dir großzügig verlichen".

(4) Vgl.M.-C. Ludwig, SANTAG 2, S. $166 \mathrm{ff}$. zu einer rezenten Edition der Hymne Išmedagan V, in der der König in den Zcilen 1-20 scine Fähigkciten in der Schreib- und Gcsangeskunst preisen läßt. ${ }^{159}$ Vgl. zu dieser Problematik W. von Soden, Mesopotamien. Tradition und Innovation in der zweisprachigen Kulrur Babylonicns, in: Erzichung und Schule zwischen Tradition und Innovarion. Herausgegeben von J. G. Prinz von Hohenzollern, U. Krebs, M. Liedtke (Bad Heilbrunn 1992), S. 122; R. F. G. Swcet, The Sagc in Mesopotamian Palaces and Royal Courts, in: J. G. Gammic u. L. G. Perdue (eds.), The Sage in Israel and the Ancient Near East (Winona Lake 1990), S. $99 \mathrm{ff}$.

159 Welche Konsequenzen eine solche militärische Karriere haben konnte, beschreibc Jamșūm aus Mari, der ciner Garnison in Ilanșurā vorstand: $i s ̌-t u$ se-eb-re-ku I.U. $U_{1}$. AGA.US ${ }_{2}-t a m-m a$ at-[ta-a]l-

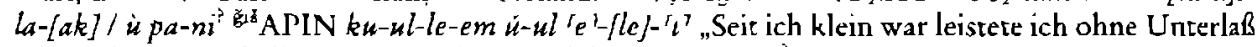
Militärdicnst. Deshalb kann ich nicht einmal den Pflug vorne? halten" (AEMI I/2, Nr. 333, Z. 10-11, vgl. hierzu D). Charpin, op.cit., S. 106 c)). Jamsūm ist also von klcin an derart ausschließlich mit seiner Karriere beim Militar beschäftigt, daß er sich nicht einmal mit einem Subsistenzfeld abgeben kann.

1ta Zu den apologerische Züge tragenden literarischen Produkten, die gerade diejenigen Herrscher des Alten Orients hinterließen, die auf irrcguläre Weisc zur Macht gelangten, vgl. H. Tadmor, History, Historiography and Interpretation, S. 36f. mit Anm. 1.

tw1 Als solche fungiercen Ammen für die Prinzessinmen (s.o., Anm. 61). Die Prinzen waren sowohl mit Gelchrten (um-mi-a/ummiänu), aber auch hohen Palastbeamten umgeben, so etwa der junge Aššureçelìāni, der nach dem Tode seines Vaters Assurbanipal von Sinšumalīsirir, dem unter Assurbanipal hochverdienten Obereunuchen', betreuc und auf den Thron gcbracht wurde: [u]ltu 'AD' ba-

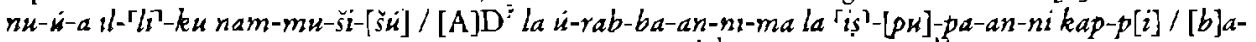

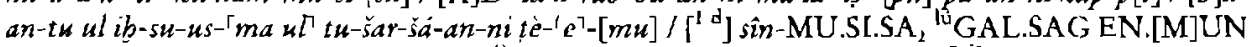

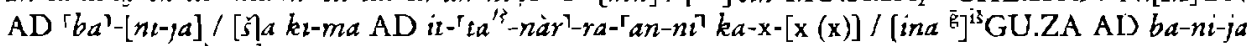

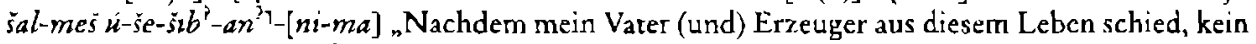
Vater mich großzog und flügge machte, keine Mutter meiner gedachte und mir Erzichung zukom- 
Staatsmann und König zu verhalten hatte. $Z$ war liegt uns keine Darstellung eincr solchen Situation aus dem 3. oder 2. Jahrtausend vor. Vielleicht aufgrund des Fundzufalles, vielleicht abcr auch, weil man solches nicht für erwähnenswert hielt. Erst der spätbabylonische König Nabupolassar schildert uns, wie er seine beiden noch kleinen Söhne Nebukadnezar ${ }^{162}$ und Nabûšumalı̌šir zur Grundsteinlegungszeremonie von Etemenanki, der berühmten Ziqqurat Babylons, einbezicht, und ihnen in diesem Kontext bereits besondere repräsentative Aufgaben zuteilt: ${ }^{163}$

\author{
„Nebukadnezar, \\ den crstgeborenen Sohn, \\ meinen Herzensliebling, ließ ich (Nabupolassar) \\ Ton, (i. e.) eine Mischung aus \\ Wein, Öl und Harzholz \\ zusammen mit meinen Bauarbcitern \\ überbringen. \\ Nabûšumalīšir, scinen Lieblingsbruder \\ mein eigenes Kind, \\ den jüngeren Bruder, \\ meinen Liebling, \\ ließ ich I Jacke und Schaufel \\ ergreifen. ${ }^{164}$ \\ Den Tragkorb \\ aus Gold und Silber legte ich ihm auf".
}

men ließ, da installierte mich Sinšumalǐšir, der Obereunuch?', der Günstling meines Vaters (und) Erzeugers, der mich wie ein Vater beständig betreute, sicher auf dem Thron meines Vaters (und) Erceugers" (vgl. J. N. Postgate, St.['ohl SM 1, Nr. 13, Vs. 4-9//Nr. 14, Vs. 4-8).

162 Wann Nebukadnezar (gest. 562 v. Chr.) geborcn wurde, ist bis jet\%t unbckannt. Zum Zeitpunkt des nachfolgend geschilderten Freignisses, der Arbeiten seines Vaters Nabupolassar an Etemenanki (ca. 620 v. Chr), war er sicherlich noch cin klcines Kind. Erst 13 Jahre spätcr (607 y. Chr.) wird er Kronprinz (mâr šarri ša büt redûti) genannt und befehligt seine eigenen Truppen. Vy!. zum historischen Kontext D. J. Wiseman, Nebuchadrezzar and Babylon (paperback edition, New York 1991), S. 12.

${ }^{163} \mathrm{Zu}$ der Inschrift, die auf je einem 'lon- und einem I Iohlzylinder überlicfert ist, vgl. P.-R. Berger, AOAT 4/1, S. 142 f. (Nabopulassar 'Zylinder III, 1; Textzeugen: BE 1/1 84 iii 7-24; ZA 4 (1889), 5. 133 f. ii 114 - iii 131; die Zejlen\%ählung folgc S. Langdon, VAB 4, S. 62): (ii 71) $n a-b r-u m-k w-d u-$

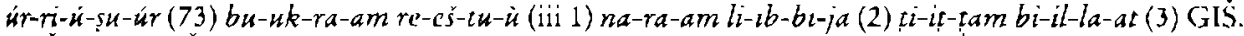

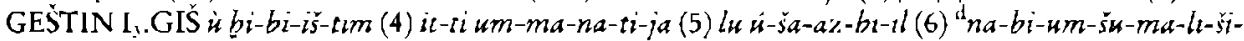

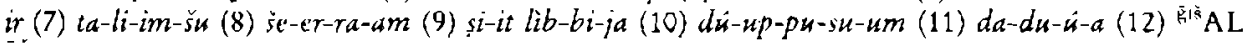

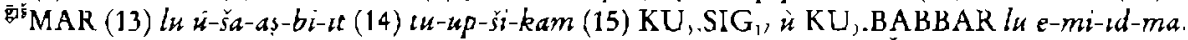
${ }^{1 n t}$ Angcsichts dieser Schilderung wird man dic Annahme relativieren, Sulgis bautechnische Kenntnisse und Erfahrungen gingen ausschlicßlich auf das Edubba'a 'rurück (s. J. Klcin, RA 80 (1986),

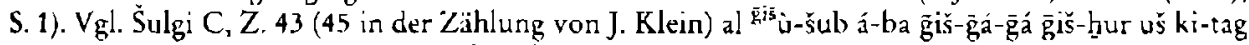
Die entsprechende Arbeitsleistung für (dic Bauarbeit mit) Hacke (und) Zicgelform festzusetzen, Baupläne zu zeichnen, ein Fundament zu legen, (darin bin ich vollendet"). "Iexte: (A) G. R. Casteliino, St.Sem. 42, Fig. 20, CBS 7079 obv iii 2; (B) SRT 14 rev. 43 (Var.: (g̈iš-hur); (E) N 993 abv. 8 (Var.: á-bi); zu dicsem unveröffentlichten l'cxtzeugen vgl. J. Klein, R $\wedge$ 80 (1986), S. 2, Anın. 4. 
Wenn auch diese Inschrift Nabupolassars erst aus der spätbabylonischen Zeit datiert, so dürftc kaum Zweifel daran bestehen, daß auch die Prinzen der vorangehenden Jahrhunderte, gleich ihren nicht-höfischen Altersgenossen bereits früh mit den beruflichen Aktivitäten ihres Vaters konfrontierr ${ }^{165}$ und ebenso früh wie systematisch in ihre Verantwortung eingebunden wurden. Hierin unterschieden sic sich also wenig von den Kindern anderer Schichten, wie etwa den Kindern von Fischern, Holzfällern, Weberinnen oder Mahlmägden, die sobald sie irgend konnten, ihre Eltern bei der Arbeit unterstützten.

Waren die Prinzen crst einmal groß genug, so wurde es, zumindest in wenigen, gut dokumenticrten Fällen für sinnvoll erachtct, sie außer Hauscs zu schicken, damir sic sich mit den Gepflogenheiten anderer Herrscherhäuser auscinandersetzen konnten. Sicherlich haben dabei massive politische Intcressen des Vaters oder der königlichen Familie eine Rolle gespielt, wenn es darum ging, wohin nun ein junger Prinz zum "Austausch" geschickt werden sollte. Ein nicht ganz vollständiger Brief aus dem altbabylonischen Mari sowie einige ergänzende Texte berichten sehr anschaulich davon, wie König Hammurapi von Babylon seinen ältesten Sohn Sumuditāna ${ }^{166}$ an den Hof König Zimrilims nach Mari schickte, um ihm alsbald scinen jüngeren Bruder Mutunumaba ${ }^{167}$ folgen zu lassen, mit der Auflage, daß beide an verschicdenen Orten unterzubringen seien: $^{168}$

\author{
„Zu meincm Herrn (Zimrilim) \\ sprich: \\ Folgendermassen Jarimaddu, Dein Diencr: \\ Uammurapi hat Mutunumaha, scinen Sohn, \\ zu meinem Herrn geschickt. \\ Ferner schrieb er meinem Herrn so:
}

ios Einen sicheren Hinweis hierauf geben die oben zitiercen spätsargunuschen Urkunden RTC 221223, wonach die sargonischen Königskinder während des Aufenthaltes iturer Eltern in Girsu anwesend waren und im Rahmen eleerlicher Dienstpflichcen möglicherweise ebenso cigene Aufgaben zu übcrnehmen hatten.

ıns Vgl. A. 183 (B. Lion, GS Birot, S. 221-222), Vs. 5-10-Rs. 1 'ba-am-mu-r[a-p]í ma-ra-su ra-bé-

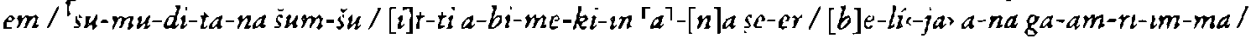
$[m] a-b a-a r b e-l i-j a /[\approx a-s] a-b i-i m /[i t]-r u-s d$, Jammurapi hat seinen ältesten Sohn, Sumuditana ist sein Name, mir Abimekim zu mcincm Herm (Zimrilim) geschickt, um vollständig bei meinem Hern zu residieren".

16) M. 9492 (s. B. Lion, GS Birot, S. 224) Rs. 12' erwàhnt dic Ankunft von Mutunumaba in Mari zusammen mit einem Bcgleiter (a-li-ik $i-d i-s ̌ s)$.

Isa ALM I/2 375 [A.3269], Z. 1-20: Vs. (1) a-na be-li-ja /(2) qi-bi-ma /(3) um-ma ja-ri-im- ${ }^{\mathrm{d}} \mathrm{I}[\mathrm{M}$

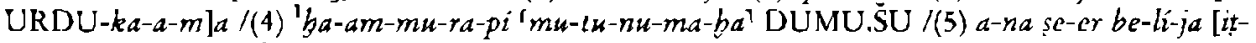

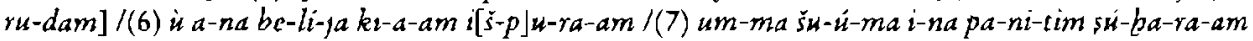
$r a-b \dot{c}-\epsilon m /(8) a-n a s e-r i-k a$ at-ru-da[m] /(9) ma-ab-ri-ka wa-si-ib i-na-an-na a-nu-rum-ma'/(10)

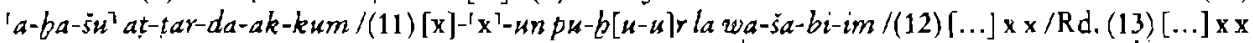

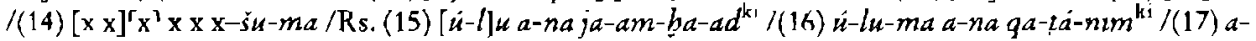

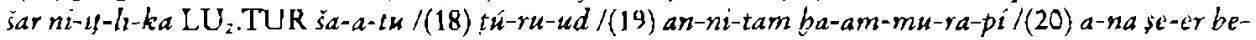
li-ja $[i s]-p u-r a-a m$ 
Folgendermassen cr: Voran habe ich den großen Burschen ${ }^{169}$ zu Dir geschickt.

Er hält sich nun bei Dir auf. Hiermit schicke ich Dir jetzt

(auch) seinen Bruder.

[...] laß sie nicht zusammen wohnen! ${ }^{170}$

(2 Zcilen abgebrochen)

... ihn und

entweder nach Jamhad

oder nach Quatna,

wo es Dir gut dünkt,

schicke diesen Jungen!

Dieses schrieb Hammurapi

meinem Herrn!"

Der von umfangreichem Gefolge begleitcte Aufenthalt ${ }^{171}$ der Prinzen dürfte, wenn die Texte dies auch nicht ausdrücklich betonen, sehr wohl einc erzieherische Note beinhaltet haben, denn im Rahmen des ${ }_{n}$ Austausches" oder Informationsaufenthaltes waren die Prinzen ohne Zweifel mit den Strukturen und Persönlichkeiten anderer, ,befreundeter ${ }^{4}$ Königshöfe konfrontiert ${ }^{172}$ und konnten sich sozusagen vor Ort mit anderen ökonomischen, aber auch militärischen Organisationsformen vertraut machen. Dies war für einen Prinzen in jedem Falle von Bedeutung, ganz gleich ob er an den Hof des Gastgebers als Sohn eines momentan alliierten Königs kam, oder ob er sich als potentieller Kontrahent mit den lokalen Verhältnissen vertraut machen wollte. Wenn es, soweit wir wissen, nicht zu cinem dirckten "Austausch“ der Prinzen von Babylon und derjenigen von Mari kam, so mag das daran gelegen haben, daß Zimrilims Söhne zum gegebenen Zeitpunkt noch zu klein waren. ${ }^{173}$ Inwieweit es sich bei dem Aufenthalt von jungen Prinzen an befreundetcn Königshöfen um eine generelle Gepflogenheit, oder nur um den systematisch gesuchten und kultivierten Kon-

169 Die Wortwahl dieser Zeile (sú-bu-ra-am ra-bé-em) ist auffällig, da inan für einen Sohn Hammurapis nicht den Terminus subārum "Bursche" erwartet, der in der Mehrzahl der Belege aus Mari einen suzialen Status bezeichnet. Vielleicht ist die Wahl dieses Ausdruckes an dieser Stelle stilistisch bedingt: Spricht Hammurapi von seinen Söhnen, so wird jedesmal zumindest eine andere Schreibweise gewählt: dumu (Z. 4), șbărum (Z. 7), lú-tur (Z. 17).

17: Wörtl.: "Bringe (sie) nicht zum Wohnen zusammen". Vgl. zu dieser Zeile D. Charpin, AFM I/2, S. 186; B. Lion, GS Birot, S. 232, Anm. 31. Der Zcilenanfang ist ganz, unsicher.

171 S. B. Lion, GS Birot, S. 222 sub c); S. 228. Nach ARM 287 (= B. Lion, GS Birot, S. 225, Nr. 121bis), Z. 22 ff, mußte Aqba'ahum, eine hochrangige Persönlichkeic aus Terqa, anläßlich des Aufentbaltes von Sumuditāna in Terqa sein Anwesen für den babylonischen Prinzen räumen.

17 Ein solcher Zusammenhang liegt wohl in AEM I/2, Nr. 537, R.s. 1'-9' vor. Jatarami, offenbar minderjähriger oder zumindest unerfahrener Sohn des verstorbenen Königs Aplahanda von Karkemiš, soll sich zur Anleitung zu Zimrilim, König von Mari, begeben (AEM I/2, Nr. 537, Rs. 5' -9'): ѝ เ-

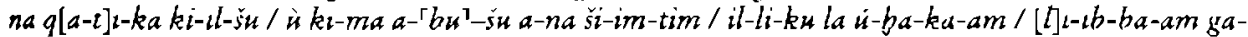
$a m-r a-a m /[u t-t] i-\check{s} u d u-b u-u b{ }_{n}$ Ferner: Leire ihn (Jatarami) an (wörcl.: halte ihn in Deinen Händen)! Weil sein Vater gestorben ist, mangclt es ihm an Erfahrung (wörtl: versteht er (noch) nicht; vgl. hierzu J.-M. Durand, AEM I/2, S. 530, sub d)). Sprich offenen Herzens mit ihm“.

${ }^{\prime \prime}$ Vgl. D. Charpin, M.A.R.I. 4, S. 338, Anm. 227; ders. AtM I/2, S. 143, Anm. 30. 
takt unter den zu jener Zeit herrschenden amurritischen Familien handelt, läßt sich aufgrund der Quellenlage nicht entschciden, doch dürfte Hammurapi seine beiden Söhne wohl nicht zufällig an die beiden bedcutendsten amurritischen Höfe jener Zcit entsandt haben. ${ }^{174}$ Jedenfalls kann es als weitgehend gesichert gclten, daß sich die Söhne Hammurapis in der Fremde frei und nicht als politisches Faustpfand ${ }^{175}$ in spannungsvollen Zeiten aufzuhalten hatren und zu gegebener Zeit nach Babylon zurückkehrten.

Etwas unerfreulicher scheint dagegen das Los der Prinzessinnen gewesen zu sein, denn insbesondere sic mußten sich den politischen Interessen des Königshauses untcrwerfen. Manche Prinzessin, wic schon Enhleduanna, Tocherer Sargons von Akkade, wurde zur Priesterin bestimmt. ${ }^{176}$ Die Mehrzahl der Prinzessinnen hingegen, wie jene zahlreichen und gut dokumentierten am Hofe Zimrilims ${ }^{177}$ in Mari oder auch schon in Ebla ${ }^{178}$ wurden im Rahmen der herrschenden Bündnispolitik an die Notablen des Landes, an befreundete oder alliierte Fürsten verheiratct. ${ }^{179}$ Nur ganz wenige hatten dic Kraft und Möglichkeit, sich gegen den ihnen vorbestimmten Lebensweg zu stemmen. ${ }^{180}$

Waren die Prinzen nun imstande zu lesen und zu rechnen, hatten sie das Tätigkeitsfeld ihres Vaters in seinen verschiedensten Facetten kennengelernt

17 Vgl. D. Charpin, AEM 1/2, S. 143; B. Lion, GS Birot, S. $232 \mathrm{ff}$.

1" Wie etwa die Kinder des Turukkäerkönigs Zazija, die jener als ,Zcichen der Bündniseinheit' zu Zazum, dem Gutäcrkönig schickte, vgl. AEM I/2, Nr. 491, Rs. $27-29^{\mathrm{T}} z a^{-}-z i-j a$ IJUMU.MES-

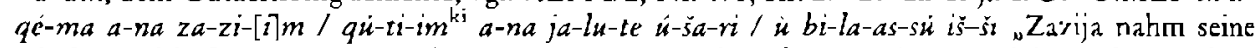
Kinder und ließ sie zu Zazum, dem Gutäer zum (Zeichen des) Bündnis(ses) führen; ferner überbrachte er seinen Tribut". AEM I/2, Nr. 525, Rs. 25-27 weist dieselbe Aussage (Var: a-na șe-er za$z i-i[m]$ auf.

1" Vgl. B. Lafont, CRRA XXXILL, S. 121; xum Zeitpunkt von Wcihung und Amtseinset»ung der ughab̆um, sowie der ēnum/ēntum-Priesterinnen, vgl. C. Wilcke, FS Kraus, S. 446f. mit Anm. 33; A. und J. Westenholz, AoF 10 (1983), S. 387-388 zur Erwählung von Tūtanapšum als Priesterin im Fkur. Auch im Alten Ägypten hatten viele Prinzessinnen Pricstcrinnenämter inne, vgl. E. Feuch Geburt, Kindheir, Jugend und Ausbildung (wie Anm. 17), S. 251.

17 Fs ist unklar, wievicle der am Hofe Zimrilims genannten Prinzessinnen tatsächlich als seine Töchter anzusehen sind, vgl: hicrzu B. Lafont, CRRA XXXIII, S. 121.

$1 / x$ Vgl. M. G. Biga, CRRA XXXIII, S. 45.

17 Vgl. rusammenfassend B. Latont, CRRA XXXIII, S. 120f. mit Tabcllc S. 120. Interessant ist die Beobachtung, daß Zimrilim scinc 'Iöchter ausschließlich an hohe Funkcionäre und allierte Fursten verheiratete, ncht aber an dic konkurrierenden Familien der großen Monarchen jener Zeit, sei es Babylon, Larsa, Ešnunna, Susa, Aleppo, Qatna oder Ekallātum.

${ }_{140}$ Fin geradezu dramatisches Beispiel gibt hierfür Kirûm, einc der Töchrer 'Zimrilims. Zwei Jahre nach ihrer Schwester Ṡimātum wurde sie von Zimrilim an den glcichen Mann, Hajjasumu von Ilanșurā, verheirater. Zimrilim wollte sich offenbar bei Hajjasumu tür geleistete militärische I Filfe dankbar zeigen. Kirûm zcrstriec sich nun nicht nur mit ihrer Schwester Sīmārum, sondern auch mit ihrem Gatten, indem sie in Ilanșurā ein anderes politisches Lager als dasjenige ihres Gatten unterstütree. Kirùm verwcigerte Hajjasumu schließlich die Gefolgschaft, worauf ihr dieser mit dem Tode drohte. Die bekümmerte Kirûm ( $\mid i-n a m u-r u-u] s ~ l i-i b-b i-i m$ wa-aś-ba-k/uJ ,ver\%weifelt sitze ich hier" AEM I/2, Nr. 315, Z. 45) wollte umgehend nach Mari zurückkchren, um die Trennung von Uajjasumu auch räumlich zu vollziehen. Ob dies gelang, ist nicht ganz sicher. Vgl. hierzu D. Charpin, AEM I/2, S. $44 \mathrm{ff}$. mit ältcrer Liveratur. 
und bereits an fremden Höfen erste Erfahrungen gesammelt, so mußten sie sich, um ein respektierter Herrscher zu werden, auch die für dicse Position notwendigen athletischen und waffentechnischen Kenntnisse aneignen. Dazu bedurfte es natürlich eines geziclten und regelmäßigen Trainings unter erfahrener Leitung, wovon in den keilschriftlichen Quellen des 3. und 2. Jahreausends nie in ausführlicher Form die Rede ist. Stereotype Epitheta wie ur-saḡ = qarrādu ${ }_{\text {„Held }}{ }^{181}$ und literarische Floskeln verraien wiederum nur das Endergebnis einer vorausgegangenen Ausbildung. Einzig der neuassyrische König Assurbanipal schildert uns in einem autobiographischen Ausschnitt seiner Kindheit und Jugend - ohne Parallele in ihrer Ausformulicrung ${ }^{182}$ - wie seine sportliche und militärische Erziehung aussah. Dieser Lebensabschnitt war eingebunden in den äußerst erfolgreichen Besuch der Schule und der intensiven Mitwirkung an politischen Entscheidungen seines Vaters: ${ }^{183}$

Nabū, der Schreiber von Allem hat mir das Erlernen seines Wissens zum Geschenk gemacht.

Ninurta und Nergal ließ meinem Körper Stärkc, Männlichkeic (und) Kraft ohneglcichen zukommen.

Die Kunst des weisen Adapa habc ich erlernt, die verborgenc(n) Geheimnis(se) des gesamten Schreibwesens,

Der ,Zeichen“ von Himmel und Erde kundig, sicze ich beratend in der Versammlung der Meister.

(Dic Omenserie), Wenn die Leber das Spicgelbild des Himmels (ist) mit den fähigsten Ölwahrsagern interpretierend,

pflegte ich (auch) komplizierteste Reziproke und Multiplikationen, ${ }^{184}$ die nicht (leicht) zu durchschaucn sind, zu lösen.

${ }_{181}$ Vgl. die Belege bei M.-J. Seux, Épithètes royales, S. $229 \mathrm{ff}, ;$ S. 459.

182 Vgl. H. Tadmor (wie Anm. 160), S. 48.

1 19 Assurbanipal L" (K 3050+K2694; vgl. M. Streck, Assurbanipal, S. 252 ff.; Th. Bauer, Assurbanipal

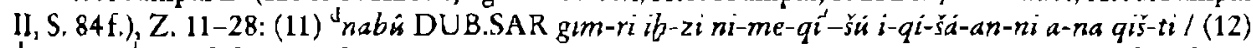

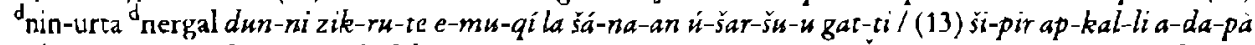

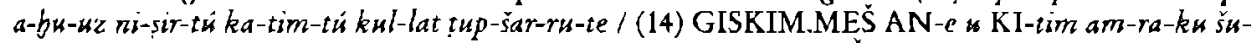
ta-du-na-ku ina UNKEN $k m-m a-a-n i /(15) \zeta s-t a-b u-l a-k u$ DIŠ BA,-ut ma-ak-lat AN-e it-ti

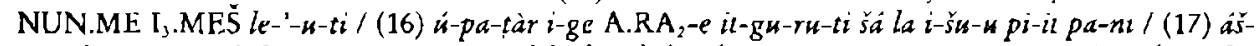
ta-si kam-mu nak-lu sa EME.GI ș-ml-lu-lu ak-ka-dk-u ana su-te-su-ri aś-tu / (18) bi-ta-ku GU,.SUM ab-ni ̌ă la-am a-bu-bi sáa kak-ku sa-ak-ku bal-lu/(19) it-tỉ il-li na-as-qi an-na-a sáa ep-

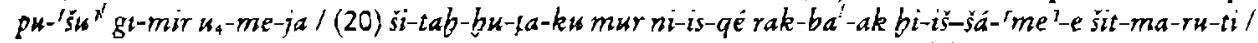
(21) [t]am-b̧a-ak til-pa-nu ú-șúu-šap-ra-ášst-mat qar-ra-du-ti / (22) a-šal-lukt-ma šil-ta-biaz-ma-

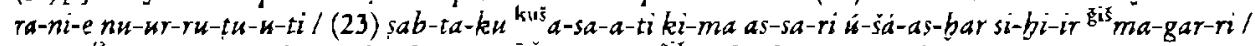

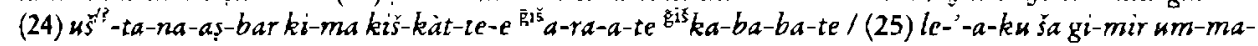

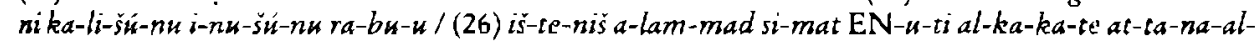

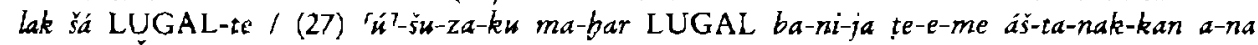
GAL.MEŚ / (28) ba-lu-u-a LU LAM $_{\text {ul }}$ ip-pa-qid LU, GAR-nu ul iš-šá-kan ul-la-nu-u-a

${ }^{114}$ Diese Aussage ist insofern bemerkenswert, als die altbabylonischen Edubba'a-Texte wie auch Sulgi B (Z. 17, 5.0., Anm. 148) im Zusammenhang der mathematischen Ausbildung in der Schule eher das Addieren ( $\overline{\mathbf{g}} \mathbf{a}-\overline{\mathrm{g}} \mathbf{a})$ und Subtrahieren (zi-zi) erwähnen, die Schultexte jedoch hauptsächlich Multiplikations- und Reziprokenübungen nachweisen. Vgl. zu diesem Befund K. R. Nemet-Ncjat, 
Ich habe kunstvoll (geschriebene) Tafeltext(e) gelesen, deren Sumerisch ,verdeckt' ist, sowie das schwer zu deutende Akkadisch.

Ich bin in der Lage, dic (in) Stcin (eingemeißelten) Schriftzeichen (aus der Zeit) vor der Flut zu crgründen, (ebenso wie) die der, vermischten' (Komposition/Kompilation namens) kakku sakku. ${ }^{\text {ss }}$

Mit ausgewählten Partnern pflegte ich täglich das Folgende zu tun:

Stets auf ausgesuchten Fohlen galoppierend, ungestüme Hengste reitend (und)

den Bogen haltend, pflegte ich den Pfeil als Zeichen meiner Kampftüchtigkeit flicgen zu lassen.

Federnde Lanzen pflegte ich genauso wic Pfeile abzuschießen.

Die Zügel fassend wie ein (profcssioncller) Wagenlenker, pflegte ich (auch) den Radkranz für das (Wagen-) Rad zu biegen.

Schilde (und) Schleudern pflegte ich regelmäßig wie ein Waffenschmicd zu verfertigen.

Die umfassenden Fachkenntnisse aller H landwcrker insgesamt beherrschend,

pflegte ich das für die Herrschaftsausübung Wesentliche zu erlernen, stets verhielt ich mich wic cin König. ${ }^{186}$

Vor dem König, meinem Erzeuger stehend, pflegte ich den Fürsten regelmäßig Anweisungen zuteil werden zu lassen.

Ohne mich wurde üblicherweise keinem Verantwortlichen (ein Amt) anvertraut, ohne meine Mitwirkung kein Statthaltcr eingesetzt".

Mag hier auch die eine oder andere Formulierung Assurbanipals vor dem zeitgeschichtlichen Hintergrund des crsten Jahrtausends zu sehen sein, so läßt sich doch wiederholt eine direkte Verbindung zu den oft so lakonischen Aussagen der Hymnen der Ur-III-Könige herstellen. Abgesehen von der eher allgemeinen Feststellung, Assurbanipal wie Šulgi hätten sich zu Schulzeiten mit Sumerisch und Akkadisch, mit Schreiben und Rechnen beschäftigt, so rühmt sich auffälligerweise auch schon König S̆ulgi, eine Experte der Ölwahrsagung zu sein. ${ }^{187}$ Ebenso läßr sich, wenn nicht für Sulgi, so doch zumindest für Ibbisîn, den letzten großen Herrscher der Ur-III-Zeit, vermuten, daß auch er mit standes-

JNES 54 (1995), $241 \mathrm{f}$.: „Addition and subtractions arc seldom mentioned as part of the mathematical curriculum “ ... „To date however, no evidence has been found for how the fact families of addition and subtraction were learned" ... Numcrous mulciplication tables and corresponding standard reciprocal tables have been found at different sitcs, attcsting to the extensive use and the homogeneous character of these learning devices".

iss Dic Interpretation der zweiten Zeilenhälfte als (Komposition/Kompilation namens) kakku sakkes beruht auf ADD 943(+)944 i 16': $13 k a k-k u s a k-k u$ „ein (Polyptychon von wachsbeschichteten Holztafeln mit) drei (,Seiten' der) kakku sakku (-Komposition)“. Zu dem genannten Text, sowie den möglichen Interpretationsansätzen des Terminus kakku sakku s. S. Parpola, JNES 42 (1983), S. 12; S. 22; vgl. auch auch CAD S, S. 78, sakku A b) „obscurc(?)“; zu den früheren Deutungen s. CAD K, S. 137 sub c); CAD B 41 sub f).

tw" Wört.: "stets gehe ich den Weg des Königtums".

"* Sulgi C, Z. 100 (102 in der Zahlung von J. Klein) ì-gíd níg-na-ri-ga-SIG -re á-bi-šè in-ga-zu "Außerdem kenne ich mich (in der Kunst der) Ölwahrsagung und der Rauchwahrsagung genauestens aus" (Texte: (A) G. R. Castellino, St.Sem. 42, Fig. 20, CBS 7079 rev. 4' (,SIG ${ }^{\prime}=$ IGI.PI); (C) STVC 50 obv. 18 (,SIG ${ }_{5}{ }^{\circ}=$ IGI.PI); (F) STVC 51 rev. 31 (,SIG ${ }_{5}{ }^{\circ}=$ IGI.AŠ.ERIN); vgl. zu dicser Zeile J. Klein, GS E. Y. Kutscher, XVf. 
gemäßen, ausgewählten Parenern Abschnitte seiner Jugend verbrachte, ${ }^{188}$ wenn man den Titel Sînabūšus du uc $_{\mathrm{c}}$-ús-sa-nam-dumu "Jugendfreund (des Ibbisîn)" in dieser Weisc interpretieren darf. ${ }^{189}$ Wenn wiederum Sulgi sich rühmt, ein überaus athletischer, waffenkundiger Kricger ${ }^{190}$ zu sein, so werden auch seine Fähigkeiten auf cin intensives und regelmäßiges Training (s.o. Z. 19) zurückgehen, ähnlich dem von Assurbanipal geschilderten. ${ }^{191}$

Spricht Assurbanipal am Ende seincr Ausführungen davon, daß er gemeinsam mit seinem Vater den Fürsten Anweisungen zuteilwerden lies und keine wichtige Personalentscheidung ohne ihn getroffen wurde, so verfügtc er zu diesem Zeitpunkt sicherlich schon über cinige Erfahrung, die ihn zu solchem Handeln befähigte. Möglicherweise war er dabei im Laufe seiner Erzichung und Ausbildung mit einem aus dem 1. Jahreausend überlieferten Kompendium konfrontiert worden, dessen Textgeschichte sich noch nicht bis an dic Anfänge zurückverfolgen läßt. ${ }^{192}$ Klar wird jedoch, daß es auf Kreise zurückgeht, ${ }^{193}$ die in subtiler Weise Einfluß auf das von ihnen als politisch opportun angesehene Auftreten und Handeln eines Prinzen gegenüber den Mächtigen des Landes, den königlichen Beratern und nicht zuletzt den Untertanen Einfluß zu nehmen

เ6 Im Alten Ägypten verbrachten die Söhne hoher Beamter Teile ihrer Jugend, so z. B. die Schulıeit, mir den Prinzen. Vgl. hier»u H. Brunner (wie Anm. 16), S. 16.

${ }_{18 *}$ Vgl. F. Yildiz/T. Gumi, FAOS 16, Nr. 916 (IS2 xi 3), Sicgelinschrift zur Urkunde: (i) di-bi- $\mu^{d} \sin$

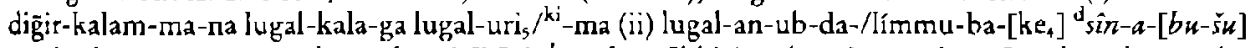
sag[i] du $u_{10}$-ús-[sa]-nam-dumu-ka-ni-[ir] in'-na-ba "Ibbisîn, der Gott seines Landes, der starke König, der König von Ur, der Köníg der vier Weltgegenden, hat Sinnabūšu, dem Mundschenken, seinem Jugendfreund (dieses Siegel) geschenkt". Zu dicser Siegellegende, sowie dem weiteren Exemplar M. Sigrist, TE.NUS, Nr. 210, s. C. Wilcke, N.A.B.U. 1989, Nr. 4.

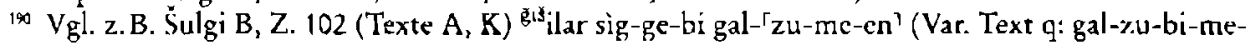
en) "(was) das Werfen des Wurtholzes (anbetriffr), so bin ich (darin) sehr erfahren" (Var. Text J: siggge-dè; Text k: sìg]-ge-da „(das Wurtholz) zu werfen“. In Šulgi D, Z. 179-188 wird eine ganze Anzahl von Kriegswaffen aufgezählr, die Sulgi für seinc Gegner bereithält, vgl. hierzu zuleczt B. Eichler, JAOS 103 (1983), S. $97 \mathrm{f}$.

\$1 Assurbanipals Schilderung, wonach er nicht nur durch incensives und regelmäßiges Training die Waffen des Kriegers und Jajgers zu beherrschen lernte, sondern auch den Bau der Waffen von Grund auf crlernte und bis zur Meisterschaft brachte, ähnelt sehr den Bcrichten und Darstellungen des Altägyptischen Herrscher Amenophis II. (18. Dynastie), der von scincm Vater Thutmosis III, kompetent angeleitet wurde. Vgl. hierzu W. Decker, Sport und Spiel im Alten Ägypten (München 1987), S. $44 \mathrm{f}$. Gleiches gilt wohl für Assurbanipals Darstellung bezüglich seines Umgangs mit Pferden. Auch hier sind Parallelen zu Amenophis II. crkennbar, dessen Kenntnisse im Umgang mit Pferden offenbar sprichwörtlich waren, vgl. W. Decker, op.cit. S. $56 \mathrm{f}$.

${ }_{192}$ Zur Frage der Datierung des Textes 5. zulctzt E. Keiner, FS Diakonoff, S. 320f. mit älterer Literatur. Der Text, in jeweils einem neuassyrischen (DT 1; Kopie: W. G. Lambert, BWL, pl. 3132, aus der Bibliothek Assurbanipals) und einem früh-ncubabylonischen Exemplar (12N 110; Umschrift: M. Civil, FS Diakonoff, S. 324f.) überliefert, steht in der literarischen Tradition Babyloniens. Auf diese Überlieferung nimmt sicherlich schon der mittelbabylonische Brief 1912-5-13,2 (s. zuletzt E. Reiner, FS Diakonoff, S. $321 \mathrm{ff}$., mit ältcrer Literatur) Bezug, der sich selbst wiederum auf alte Tafeln beruft.

"s Hierin sind sicher die auch im Text (Z.5) sclbst genannten um-me-a = ummiänū "Gelchrtcn", „Weisen (Schreiber) ${ }^{\alpha}$ aus der Umgebung des Königs und Kronprinzen zu sehen. 
suchte. Schließlich mußtc sich auch ein Prinz mit der Eingebundenheit in ein bestehendes System und mit den sich daraus ergebenden historischen Gegebenheiten und Abhängigkeiten abfinden und vertraut machen, um entsprechenden Handlungsspielraum zu erlangen. Nicht von ungefähr lchnt sich der Text an die literarische Form der Omina mit seinen Protasen und Apodosen an: Dem Prinzen werden danach keine wohlcrwogenen Ratschläge erteilt, sondern mit crhobenem Zeigefinger die unvermeidlichen Konsequenzen , falschen' Handelns vor Augen geführt. Hält er sich nicht an das bestehende Recht, so stürzt er das Land ins Chaos, und $\mathrm{Ea}$ ändert das ihm bestimmte Schicksal. Mißachtet cr die Notabeln und die Erfahrung scincr Ratgeber, aber auch die Privilegien der Städte Sippar, Nippur ${ }^{194}$ und Babylon, ${ }^{195}$ so provoziert er Rebellion, den Verlust von $\mathrm{Hab}$ und Gut und sogar den des eigenen Lebens: ${ }^{196}$

(Wenn) der König sich nicht um das Recht kümmert, geraten seine Leute durcheinander, wird scin Land zur Steppe.

(Wenn) er sich nicht um das Recht seines Landes kümmert, wird Ea, der König übcr die Schicksalsentscheidungen sein Schicksal abändern und ihn ohne Unterlaß mit Unglück verfolgen.

(Wenn) er sich nicht um seine Notabeln kümmert, werden seine Tage kurz werden.

(Wenn) er sich nicht um seine Weisen kümmert, wird sein Land ihn stürzen.

(Wenn) er sich um einen Schurken kümmert, wird sich dic Einstcllung scines Landes (ihm gegenüber) ändern.

(Wenn) er sich (aber) um das Werk des Gorres Ea bemühr, so werden ihn die großen Götter mit Umsicht auf den Pfaden der Gerechtigkeit stets geleiten ". ${ }^{197}$

14 Išmedagan von 1sin verfügr den Bürgern von Nippur die Abschaffung von Abgaben und Enthebung von ihrer Kriegsdienstverpflichtung. Vgl. hierzu F. R. Kraus, SD IX, S. 17.

195 Die gemeinsame Erwähnung von Sippar, Nippur und Babylon kann sicher als datierendes Kriterium für cine nach-(?)altbabylonische Textredaktion gelten, doch dürfte der Text im Kern unabhängig vom dirckten Zusammenhang mir den genanncen Städten sicherlich auf eine alte Tradition zurückgreifen. Dafür spriche auch die Tatsache, daß die leider fast völlig verlorene 53. Tafel der Omenscric šumma àlu als einleitende Protasis šumma šarrum ana dinim iqül „wenn der König sich um das Rcchr kümmert" aufweist. Vgl. zur Überlieferungssituation von šumma ālu Tf. 53 S. Moren, Šumma ālu, S. 198.

190 DT 1, Vs. 1-7 (Kopie: W. G. Lambert, BWL, pl, 31; zu dem fruhneubabylonischen Duplikat 12N 110 vgl. dic Umschrift von M. Civil, FS Iiakonoff, S, 324f.); (1) LUGAL a-na di-ni la i-qúl

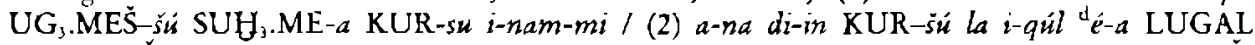

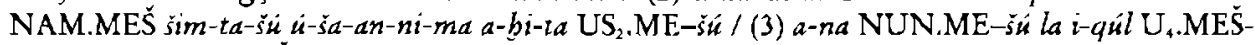

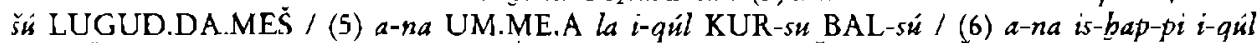

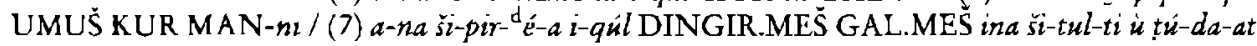

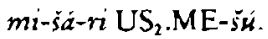

197 W. G. Lambert, BWL., S. 113 [7], [8] versteht diese Zeile, offenbar unter Annahme cines Parallelismus membronum zur Vorzeile, gegenteilig und übersetze: "If he heeds a trick of Ea, the grear gods in unison and in their just ways will not cease from prosecuting him". Mag der Kontext eine solche Deutung nahelegen, so ist die Übersetzung ${ }_{n}$ in their just ways" nach dem Akkadischen nicht gerechrfertigt. 'Zum hier vertretenen Textverständnis vgl. AHw, S. 966 sub redû(m) Gtn 1); CAD S/III, S. 143 a). 
Welchc Bedeutung die Herstellung stabiler Rechtsvcrhältnisse, auf die zu Beginn des Textes Bezug genommen wird, in der Praxis hatte, läßt sich nicht nur an den Rechtsbestimmungen crkennen, die die Stadtfürsten seit der altsumerischen ${ }^{198}$ und besonders gut dokumentiert dic Könige in der Ur-III- ${ }^{199}$ und altbabylonischen Zeit erließen. Sogar Jahresnamen trugen Titel wie "Jahr (in dem) Lipitištar, der König, in Sumer und Akkad eine gerechte Ordnung eingesetzt hat " ${ }^{200}$ Ganz glcich, ob dieser Jahresname nun den Anfang der Regierungszeit des Königs Lipitištar markiert, ${ }^{201}$ so ist er doch Hinweis genug, daß sich die Kronprinzen schon vor Beginn ihrer Regierungszeit intensiv mit ihrer zukünftigen Aufgabe als Gesetz.geber auseinandersetzen mussten. Demnach dürfte das Gedankengut des aus dem 1. Jahrtausend überlieferten Textes, des sogenannten babylonischen Fürstenspicgels, ${ }^{202}$ im Grundsatz schon bis ins dritte Jahrtausend zurückreichen.

So hatte ein Prinz der altbabylonischen Zeit wie jedes ander Kind Lob und Tadel über sich ergehen zu lassen, war mit dem Vorbild seines Vaters, aber auch mit demjenigen legendenumwobener Vorgänger aus der Vergangenheit konfronticrt. Er stand, wie vielc Beispiele aus der altmesopotamischen Geschichte zeigen, im harten, manchmal blutigen Wettstreit mit seinen Brüdern ${ }^{233}$ und hörte Ermahnungen und Appelle ohne Ende. Daneben hattc er sich spezifischen Aufgaben und einer ganz besonderen Verantwortung für das ganze Land zu gegen-

\footnotetext{
1ys Zu den sog. Reformtexten des Irikagina vgl. H. Stcible, FAOS 5/1, S. $288 \mathrm{ff}$., Ukg. 4-5.

${ }^{104}$ Vgl. F. R. Kraus, SD IX, S. 25 ff. mit zahlreichen Verweisen auf die verschiedenen Verfügungen, die Könige der Ur-III- und altbabylunischen Zeit crlassen haben.

${ }_{200}$ S. F. R, Kraus, SD IX, S. 19.

201 S. D. O. Edzard, ZZB, S. 94; F. R. Kraus, SID IX, S. 19. Auch andere Könige der altbabylonischen Zeit, wie z. B. Samsuiluna, der Nachfolger Hammurapis in Babylon, erließ gleich zu Beginn seiner Regicrungs`eir einen-mǐšrum-Erlaß, vgl. B. Lion, Florilcgum Marianum 2, S. 231, mi älterer Literatur.

${ }_{202}$ Zur Geschichte der Einführung dieses Begriffes zur Charakterisierung des Textes vgl. E. Reiner, FS 1)iakonoff, S. $322 \mathrm{f}$., Anin. 6.

2as Schon die beiden Söhne des Königs Sargon von Akkad, Mıništūsu und Rīmuš, lagen in blutigem Streit. Vermutlich war Maništūsu verantworthch für den Iỏd des jungeren Bruders Rīmuš (vgl. P. Stcinkeller, RIA 7, S. 334). Entsprechende Beispiele sind über die altbabylonischen Bricfe aus Mari dokumentiert, vgl. F. Joannès, AEM 1/2, S. 245 h) ad Nr. 401, Z. 33-34. Von besonderem Interesse ist AEM 1/2, Nr, 531, einem Bricf von Šidqulanasi an Zimrilim. Danach hatte Išmedagān Jahdunlim, Prinz in Karkemiš, aufgefordert, seine Brider zu vertrciben (7.. 9: ab-be-ka ku-ušs-si-id), um keine Konkurrenten um den Thron mehr zu haben. Jahdunlim ignorierte jedoch Išmedagāns Ansınnen:

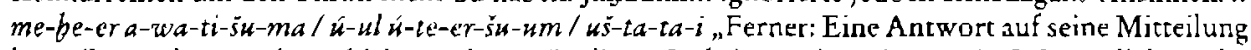
hat er ihm nicht zurückgeschickt (und) war (in dicscr Sache) untätig" (Z. 16-18). Colegentlich spielte beim Kampf un die Thronfolge die Köriginmutter dic entscheidende Rolle. Auf diese Weise wurde beispiclsweise Asarhaddon, jüngster seiner Brüder, geliebter Sohn der Königin Naqi’a-Zakūtu zum Thronerben Sanheribs. ,Offiziell' durch ein Leberomen dazu bestimmt, ließen die ältern Brüder, allen voran Aradmulissu cinschlicßlich des Mordes an ihrem Vater nichts unversucht, um diese Entscheidung zu torpedicren. Vgl. hierzu I. Tadmor (wie Anm. 160), S. 38 ff. Auch die Nachfolgc Asarhaddons war von Wirren begleitet, da niche der ältere Šamaššumukin, sondern der jüngerc Assurbanipal zum Zuge kam, vgl. HI. Tadmor, op.cit., S. $43 \mathrm{ff}$, und $52 \mathrm{ff}$. zu weiteren Beispielen aus der newassyrischen Geschichte.
} 
wärtigen, das ihn von den Altersgenosssen unterprivilegierter und bürgcrlicher Schichten unterschied. Ein Text wic der babylonische Fürstenspiegel gibt in diesem Zusammenhang einen durchaus realistischen Einblick in dic crzicherischen Methoden, ${ }^{204}$ mit denen man cinen zukünftigen Herrscher auf sein Amt und seine individuelle Verantwortung vorzubereiten suchte.

\section{Abkürzungsverzeichnis}

ABD: The Anchor Bible Dictionary (New York - London - Toronto - Sydncy - Auckland 1992)

AEM 1/2: D. Charpin-F. Joannès - S. Lackenbacher - B. Lafont, Archives épistolares de Mari L/2 (Paris 1988)

AfO: Archiv für Orientforschung, vols. 3 ff. [vols. 1-2 = $\mathrm{ffK}$ ] (Berlin, Graz and Horn 1926 ff.)

ADD: C. H. W. Johns, Assyrian Deeds and Documents Recording the Transfer of Property Including the so-callcd private contracts, legal decisions and proclamations preserved in the Kouyunjik Collections of the British Museum Chiefly of the 7th Century B.C., 4 Bde. (Cambridge 1898-1923)

AHw: W. von Soden, Akkadisches Handwörterbuch (Wiesbaden 1958-81)

AO: Antiquités orientales (Museumssignatur des Louvrc, Paris)

AOAT: Alter Orient und Altes Testament. Veröffentlichungen zur Kultur und Geschichte des Alten Orients und des alten Testaments (Neunkirchen-Vluyn $1969 \mathrm{ff}$.)

AoF: Altorientalische Forschungen (Berlin $1974 \mathrm{ff}$.)

ARM: Archives Royales de Mari (Paris $1950 \mathrm{ff}$. )

AS: Assyriological Studics (Chicago 1931 ff.)

BE: Babylonian Expedition of the University of Pennsylvania, Series A: Cuneiform Texts, 14 Bde. (Philadelphia 1893-1914)

BWL: W. G. Lambert, Babylonian Wisdom L.iterature (Oxford 1960)

CAD: The Assyrian Dictionary of the Oriental Institute of the Universiry of Chicago (Chicago/Glückstadt, $1956 \mathrm{ff.}$.)

CBS: Catalogue of the Babylonian Secrion (Muscumssignatur des University Museum, Philadelphia)

CRRA: Compte Rendu de la Rencontre Assyriologique Internationale (verschiedene Erscheinungsorte $1950 \mathrm{ff}$.)

CT: Cuneiform Texts from Babylonian Tablets in the British Museum (London 1896ff.)

CTMMA I: I. Spar, Cuneiform Texts in the Metropolitan Museum of Art, Vol. I: Tablets,

Concs, and Bricks of the Third and Second Millennia B.C. (New York 1988)

DT: Daily Tclegraph (Muscumssignatur des British Museum, London)

ÉLS: P. Átringer, Éléments de linguistique sumériennc. La construction de $\mathrm{du}_{11} / \mathrm{e} / \mathrm{di}$ (Fribourg / Göttingen 1993)

FAOS: Freiburger Altorientalische Studien (Wiesbaden $1975 \mathrm{ff}$.)

FS Birot: Miscellanea Babylonica. Melangcs offerts à Maurice Birot. Reunis par J.-M. Durand et J.-R. Kupper (Paris 1985)

${ }_{204}$ Vgl. zu diesem Ansacz E. Reiner, FS Diakonoff, S. 322. 
FS Garelli: Marchands, diplomates et empereurs. Études sur la civilisation mésopotamienne offertes à Paul Garelli. Textes réunis par D. Charpin et F. Joannès (Paris 1991)

FS Diakonoff: Societies and Languages of the Ancient Near East. Studies in Honour of I. M. Diakonoff (Warminster 1982)

FS Kraus: Zikir šumim. Assyriological Studies Presented to F. R. Kraus (Lciden 1982)

FS Lokkegaard: Living Waters. Scandinavian Orientalistic Studies Presented to Prof. Dr. Frede Lokkegaard on his Seventy-Fifth Birthday, January $27^{\text {th }} 1990$. Edited by E. Keck, S. Søndergaard, E. Wulff (Kopenhagen 1990)

Geschlechtsreife: C. Wilcke, Familiengründung im Alten Babylonicn. In: Geschlechtsrcife und Legitimation zur Zeugung (= Kindheit Jugend lamilic I, E. W. Müller, ed.). Veröffentlichungen des Instituts für Historische Anthropologie 3 (Freiburg / München 1985) 213-317

Gordon, Proverbs: E. Gordon, Sumerian Proverbs: Glimpses of Everyday Life in Ancicnt Mcsopotamia (Philadelphia 1959)

GS Birot: Mémoires de N.A.B.U. 3: D. Charpin ct J.-M. Durand (éd.), Florilegium marianum II. Recueil d'études à la mémoire de Maurice Birot (Paris 1994)

GS E. Y. Kutscher: Studics in Hcbrew and Semiric Languages Dedicated to the Mcmory of Prof. Eduard Y. Kutscher. Edited be G. R. Sarfatti et alji (Ramat-Gan 1980)

ISET: Istanbul Arkeoloji Müzelerinde Bulunan: Sumer Edcbî̀ Tablet ve Parçalari, 2 Bde. (Ankara 1969-1976)

JAOS: Journal of the American Oriental Socicty (New Haven $1893 \mathrm{ff}$.)

JCS: Journal of Cunciform Studics (New Haven - Cambridge, Mass. 1947ff.)

JEOL: Jaarbericht van het Vooraziatisch-Egyptisch Genootschap "Ex Oriente Lux“ (Leiden $1933 \mathrm{ff}$.)

JNES: Journal of Near Eastern Studies (Chicago $1942 \mathrm{ff}$.)

La Sagesse: J. J. A. van Dijk, La sagcssc suméro-accadienne. Recherches sur les genres littéraires des textcs sapicntiaux avec choix de textes (Leiden 1953)

LÄ: Lexikon der Ägyptologie. Begründet von W. Ilelck und E. Otto. Hrsg. von W. Helck und W. Westendorf. 7 Bde. (Wicsbaden 1972-1992)

M.A.R.I.: Mari. Annales de Recherches Interdisciplinaires (Paris $1982 \mathrm{ff}$.)

MSL; Materialicn zum sumcrischen Lexikon (Rom 1937ff.)

N.A.B.U.: Nouvelles Assyriologiques Brèves et Utilitaires (Roucn-Paris $1987 \mathrm{ff}$.)

NBC: Signatur der Nies Babylonian Collection (New Haven)

NG: A. Falkenstein, Die neusumerischen Gerichtsurkunden (München 1956-1957)

N-T: Nippur-Texts (Signatur für Texte aus Nippur [Baghdad/Chicago])

OLZ: Orientalistischc Litcraturzeitung (Berlin/Leipzig 1898ff.)

OPBF: Occasional Publications of the Babylonian Fund, 8 Bdc. (Philadelphia 19761984.)

OrNS: Orientalia. Nova Series (Rom 1932ff.)

PBS: Publications of the Babylonian Section, University Museum, University of Pennsylvania, 15 Bdc. (Philadclphia 1911-1926)

PSD: The Sumerian Dictionary of the University Muscum of the University of Pennsylvania, edited by A. W. Sjöberg (Philadelphia 1984ff.)

RA: Revue d'assyriologie et d'archéologic orientale (Paris 1886ff.)

RlA: Reallexikon der Assyriologie (Berlin/Leipzig $1932 \mathrm{ff}$.)

RTC: F. Thureau-Dangin, Recueil de rablettes chaldécnnes (Paris 1903)

SANTAG: SANTAG. Arbeiten und Untersuchungen zur Keilschriftkunde. Herausgegeben von K. Hecker und W. Sommerfeld (Wiesbaden 1990 ff.) 
SD: Studia et Documenta ad Iura Orientis Antiqui Pcrtinentia (Leiden 1936ff.)

SKIZ: W. H. Ph. Römer, Sumerische ,Königshymnen' der Isinzeir (Leiden 1965)

SLFN: J. Heimerdinger, Sumerian Litcrary Fragments from Nippur (OPBF 4, Philadelphia 1979)

SLTNi: S. N. Kramer, Sumerian Literary Texts from Nippur in the Museum of the Ancient Orient at Istanbul (New Haven 1944)

SRT: E. Chicra, Sumerian Religious Texts (Upland, Pa., 1924)

St.Pohl SM: Studia Pohl: Serics Maior (Rom 1969ff.)

St.Sem.: Studi Semitici (lstituto di Studi del Vicino Oricnte, Università di Roma; Rom $1958 \mathrm{ff}$.)

Streck, Assurbanipal: Streck, M. Assurbanipal und die letzten assyrischen Könige bis 7um Untergang Niniveh's (VAB 7, Leipzig 1916)

STVC: E. Chiera, Sumerian Texts of Varied Contents (Chicago 1934)

TCL: Textes cunéiformes du Musée du Louvre, Département des Antiquités Orientales (Paris $1910 \mathrm{ff}$.)

TÉL: Ch. Virolleaud, M. Lambert, Tabletres économiques de Layash (ćpoque de la III ${ }^{e}$ dynastie d'Ur) copiées en 1900 au Musée Impérial Ottoman par Charles Virolleaud. Ouvrage publié par M. Lambert (Paris 1968)

TÉNUS: M. Sigrist, Textes économiques néosumeriens de l'université de Syracuse (Paris 1983)

TMH(NF): Texte und Materialien der Frau Prof. Hilprecht-Sammlung Vorderasiatischer Altertümer im Eigentum der Friedrich-Schiller-Universität Jcna (Neue Folge, Leipzig $1932 \mathrm{ff}$.)

TUAT: O. Kaiser (ed.), Texte aus der Umwalt des Alten Testaments (Gütersloh $1982 \mathrm{ff}$.)

UFT: Ur Excavations, Texts (London $1928 \mathrm{ff}$.)

UI: Ugarit-Forschungen. Internationales Jahrbuch für die Altertumskunde SyrienPalästinas (Neukirchen-Vluyn 1969ff.)

UM: University Muscum (Signatur des University Museum, Philadelphia)

VAB: Vorderasiatische Bibliothek (Leipzig 1907-1916)

VS: Vorderasiatische Schriftdenkmäler der Königlichen Musecn zu Berlin (Berlin Leipzig $1907 \mathrm{ff.}$.)

WZUH: Wissenschaftliche Zeitschrift der Martin-Luthcr-Universität Halle-Witcenberg, gesellschafts- und sprachwissenschaftliche Reihe (Halle 1953 ff.)

ZA(NF): Zeitschrift für Assyriologie (Neue Folgc, Berlin - Leipzig 1886ff., 1924ff.)

77.B: D. O. Edzard, Die ,Zweite Zwischenzcit Babyloniens (Wiesbaden 1957) 